Lívia Delgado

\title{
Fenômeno de epitope spreading : caracterização clínico imunológica em pacientes portadores de dermatoses bolhosas autoimunes
}

\author{
Tese apresentada à Faculdade de Medicina da \\ Universidade de São Paulo para obtenção do \\ título de Doutor em Ciências \\ Programa de Dermatologia \\ Orientadora: Profa. Dra. Valéria Aoki
}

(Versão corrigida. Resolução CoPGr 6018/11, de 1 de novembro de 2011.

A versão original está disponível na Biblioteca da FMUSP)

São Paulo

2016 
Dados Internacionais de Catalogação na Publicação (CIP)

Preparada pela Biblioteca da

Faculdade de Medicina da Universidade de São Paulo

Creprodução autorizada pelo autor

Delgado, Lívia

Fenômeno de epitope spreading : caracterização clínico imunológico em pacientes portadores de dermatoses bolhosas autoimunes / Lívia Delgado. -- São Paulo, 2016.

Tese(doutorado)--Faculdade de Medicina da Universidade de São Paulo. Programa de Dermatologia.

Orientadora: Valeria Aoki.

Descritores: 1.Epitopos/imunologia 2.Dermatopatias vesiculobolhosas 3.Pênfigo 4.Epidermólise bolhosa adquirida 5.Imunofluorescência 6.Ensaio de imunoadsorção enzimática

USP/FM/DBD-094/16 


\section{DEDICATÓRIA}

A Maurício, o melhor companheiro para todas as jornadas.

Aos meus pais Juan e Isabel Cristina e irmãs Amanda e Fábia, pelo amor e apoio constante. 


\section{AGRADECIMENTOS}

Agradeço à Faculdade de Medicina da Universidade de São Paulo, pela formação e oportunidades oferecidas e principalmente por colocar em meu caminho tantas pessoas maravilhosas, as quais fizeram e fazem parte de importantes momentos da minha vida.

À minha orientadora, Prof $^{\mathrm{a}}$. Dr ${ }^{\mathrm{a}}$. Valéria Aoki, a quem tanto admiro. Uma pessoa maravilhosa que me fez amar a Dermatologia e elegê-la como formação. A pessoa que me introduziu no mundo da pesquisa científica e que possibilitou a realização deste trabalho. Agradeço seu apoio, amizade e carinho em diversos momentos decisivos da minha vida. Serei eternamente grata.

À Prof ${ }^{a}$. Dr ${ }^{a}$ Celina Maruta, por seu carinho, preocupação, exemplo e aprendizado durante minha jornada pela Dermatologia e pela vida.

A Dra . Cláudia Santi e $\mathrm{Dr}^{\mathrm{a}}$. Denise Myamoto, pelo apoio, amizade e aprendizado.

Aos funcionários do Laboratório de Imunopatologia Cutânea do Hospital das Clínicas da Faculdade de Medicina da Universidade de São Paulo: Alexandre, Lígia e Eliete, pela amizade e apoio.

Aos pacientes do Ambulatório de Dermatoses Bolhosas, cuja contribuição foi fundamental para o desenvolvimento deste trabalho.

A Maurício, pelo amor com que tem me acompanhado nos momentos importantes da vida.

Aos meus queridos pais, Juan Perez Delgado e Isabel Cristina Macedo Delgado, pelo amor incondicional e pelo valor que sempre deram à educação.

Às minhas irmãs, Amanda e Fábia, pelo carinho e apoio mesmo à distância. 


\section{Normalização adotada:}

Esta tese está de acordo com as seguintes normas, em vigor no momento desta publicação:

Referências: adaptado de International Committee of Medical Journals Editors (Vancouver).

Universidade de São Paulo. Faculdade de Medicina. Divisão de Biblioteca e Documentação. Guia de apresentação de dissertações, teses e monografias. Elaborado por Anneliese Carneiro da Cunha, Maria Julia de A. L. Freddi, Maria F. Crestana, Marinalva de Souza Aragão, Suely Campos Cardoso, Valéria Vilhena. 3a ed. São Paulo: Divisão de Biblioteca e Documentação; 2011.

Abreviaturas dos títulos dos periódicos de acordo com List of Journals Indexed in Index Medicus. 


\section{SUMÁRIO}

Lista de abreviaturas

Lista de figuras

Lista de tabelas

Lista de quadros

Resumo

Abstract

1 INTRODUÇÃO

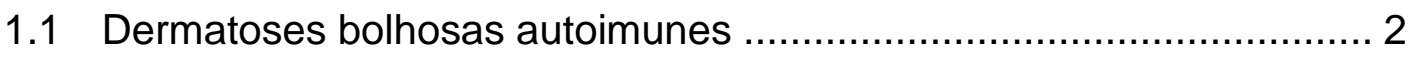

1.1.1 Dermatoses bolhosas intraepidérmicas ............................... 4

1.1.2 Dermatoses bolhosas subepidérmicas ................................. 7

1.2 Papel do epitope spreading em doenças autoimunes........................ 10

2 REVISÃO DA LITERATURA

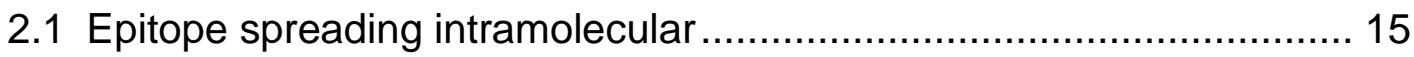

2.2 Epitope spreading intermolecular ..................................................... 17

2.3 Epitope spreading e coexistência de achados moleculares de diferentes dermatoses autoimunes............................................. 19

2.4 Epitope spreading e Coexistência de doenças autoimunes e

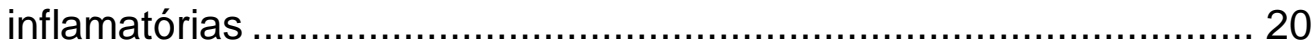

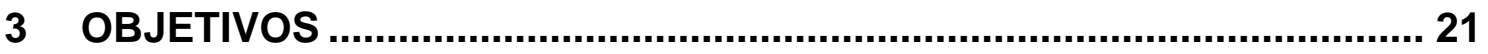

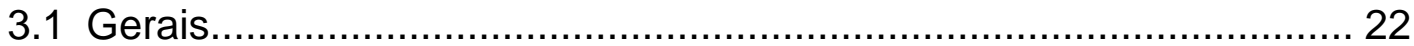

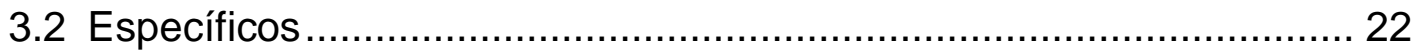

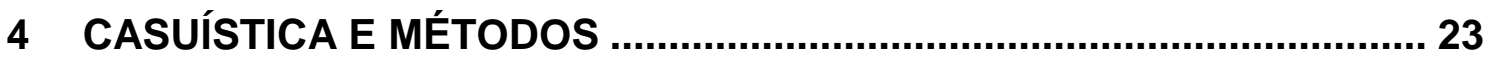

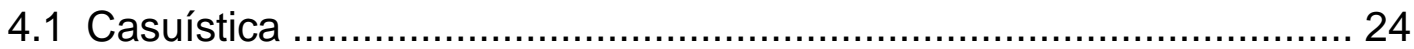

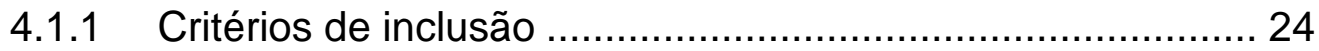

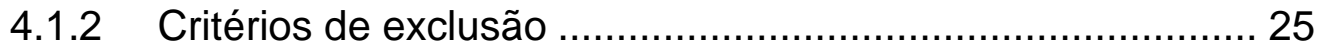

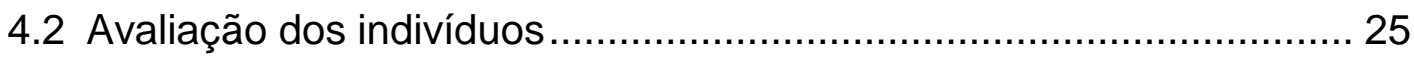

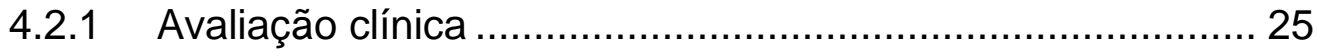

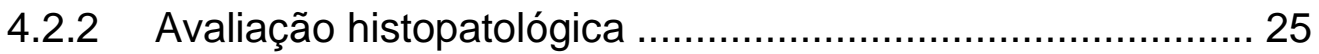

4.2.3 Avaliação de imunofluorescência e imunosorológica............. 26 


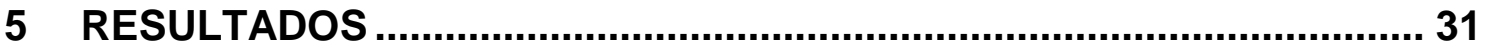

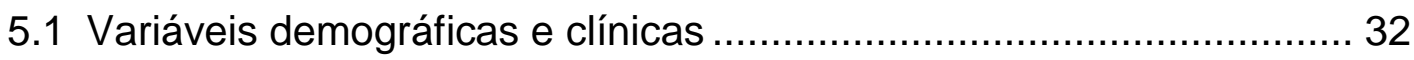

5.1.1 Variáveis demográficas e clínicas: Grupo 1 ....................... 32

5.1.2 Variáveis demográficas e clínicas: Grupo 2....................... 35

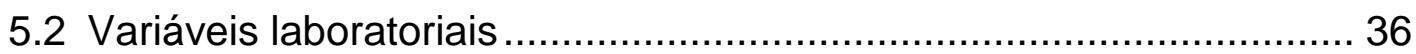

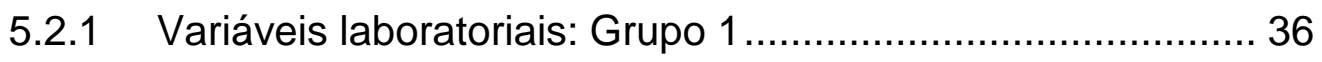

5.1.2 Variáveis laboratoriais: Grupo 2 ....................................... 42

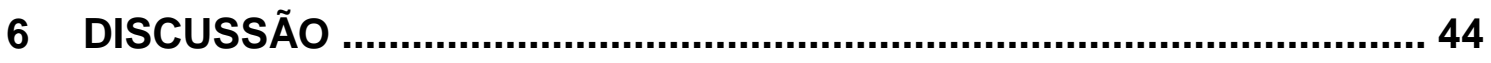

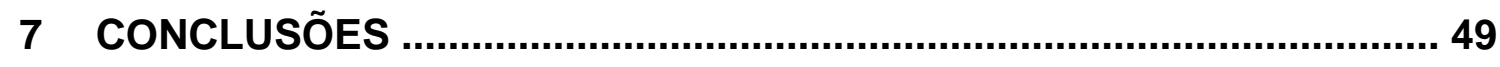

8 ANEXOS

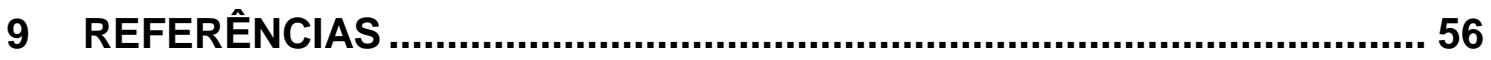




\section{LISTA DE ABREVIATURAS}

$\mathrm{DH} \quad$ Dermatite herpetiforme

Dsg Desmogleína

Dx Diagnóstico

EBA Epidermólise bolhosa adquirida

ELISA Enzyme-linked immunosorbent assay

ES Epitope spreading

HCFMUSP Hospital das Clínicas da Faculdade de Medicina da Universidade de São Paulo

HP Histopatologia

HE Hematoxilina eosina

IFD Imunofluorescência direta

IFI Imunofluorescência indireta

LB Linfócito $B$

LT $\quad$ Linfócito T

LTh Linfócito T helper

PB Penfigóide bolhoso

PF Pênfigo foliáceo

PMM Pênfigóide de membranas mucosas

PV Pênfigo vulgar

SPD Dermatose pustular subcórnea

SSS Salt split skin

ZMB Zona da membrana basal 


\section{LISTA DE FIGURAS}

Figura 1. Histopatologia nas dermatoses bolhosas autoimunes.

Figura 2. Aspecto clínico das lesões cutâneas no diferentes grupos de dermatoses bolhosas autoimunes.

Figura 3. Composição dos desmossomos..................................... 4

Figura 4. Distribuição de desmogleína 1 e 3 na pele e mucosas .................. 5

Figura 5. Histopatologia nos diferentes subtipos de pênfigo. ....................... 6

Figura 6. Representação esquemática da zona da membrana basal ............ 8

Figura 7. Epitope spreading de linfócitos T................................... 11

Figura 8. Epitope spreading intramolecular no pênfigo folíaceo endêmico. . 16

Figura 9. Padrões de imunofluorescência direta 26

Figura 10. Paciente 1: Em 2007, desenvolvimento de lesões cutâneo mucosas com diagnóstico de PV

Figura 11. Paciente 8. Lesões cutâneo mucosas no diagnóstico inicial de PV em 2008, apresentou remissão clínica 2 anos após tratamento com prednisona e micofenolato mofetila.

Figura 12. Paciente 3. Lesões cutâneo mucosas no diagnóstico inicial de PV (outubro de 2003), apresentou exacerbação da doença em 2006.

Figura 13. Paciente 3. Em 2008, suspeita de ES a PF devido modificação do quadro clínico

Figura 14. Paciente 3 . Retorno de aspecto de PV em setembro de 2008..... 41

Figura 15. Achados laboratoriais no paciente do grupo 2. 


\section{LISTA DE TABELAS}

Tabela 1. Revisão da literatura: Epitope spreading intermolecular em pacientes portadores de pênfigo

Tabela 2. Variáveis demográficas e clínicas dos pacientes do grupo 1 (PV a PF). 34

Tabela 3. Sumário dos achados laboratoriais nos pacientes do grupo 1 (PV a PF)

Tabela 4. Sumário dos valores de ELISA para Desmogléinas 1 e 3 recombinantes nos pacientes do grupo 1 antes e após a suspeita de fenômeno de ES (PV a PF): 


\section{LISTA DE QUADROS}

Quadro 1. Dermatoses bolhosas autoimunes e seus respectivos autoantígenos ..................................................................... 9

Quadro 2. Interpretação dos resultados de ELISA ........................................ 29 


\section{RESUMO}

Delgado L. Fenômeno de epitope spreading: caracterização clínico imunológica em pacientes portadores de dermatoses bolhosas autoimunes [tese]. São Paulo: Faculdade de Medicina, Universidade de São Paulo; 2016. 64p.

INTRODUÇÃO: As dermatoses bolhosas autoimunes são um grupo heterogêneo de afecções da pele e/ou mucosas associadas à produção de autoanticorpos dirigidos às moléculas de adesão epitelial. Podem ser classificadas em dermatoses bolhosas intraepidérmicas (pênfigos) ou subepidérmicas (penfigóides, epidermólise bolhosa adquirida). Nos últimos anos, a transição entre dermatoses bolhosas autoimunes ou coexistência de autoanticorpos de diferentes dermatoses têm sido relatadas em alguns pacientes e atribuída ao fenômeno de epitope spreading (ES): a diversificação de epítopos reconhecidos pelo sistema imune evocaria uma reação secundária a antígenos distintos e não relacionados aos da doença primária. Neste trabalho avaliamos a ocorrência de fenômenos de ES em pacientes portadores de pênfigo. CASUÍSTICA E MÉTODOS: Inicialmente, foi realizada análise de dados clínicos e laboratoriais (exame histopatológico, de imunofluorescência direta-IFD, indireta IFI e ELISA) de 351 pacientes portadores de pênfigos acompanhados no Ambulatório de dermatoses bolhosas autoimunes do Departamento de Dermatologia da Faculdade de Medicina da Universidade de São Paulo no período de dezembro de 2002 a dezembro de 2012. Foram selecionados pacientes com quadro sugestivo de conversão à dermatose bolhosa distinta da doença primária. RESULTADOS: Nove pacientes apresentaram sinais sugestivos de fenômeno de ES e foram incluídos no estudo: 8 com a conversão de Pênfigo vulgar (PV) a foliáceo (PF) 2,3\% (grupo1) e um de PF a Epidermólise bolhosa adquirida (EBA) 0,3\% (grupo 2). No grupo 10 intervalo mediano para a conversão foi de 3,5 anos. Cinco pacientes apresentaram modificação histopatológica de clivagem intraepidérmica na camada suprabasal para clivagem na camada subcórnea durante a suspeita de ES; 2 apresentaram clivagem na camada epidérmica média durante a transição e um manteve clivagem suprabasal, apesar de quadro clínico sugestivo de PF. Todos os pacientes apresentavam depósitos intercelulares de IgG e/ou C3 durante o diagnóstico de PV e PF à IFD. Títulos de IFI variaram de 1:160 a 1:5120. Os valores de ELISA para Dsg1 variaram de 22 a 319; e para Dsg3 de 0.4 a 224 (positivo se >20). A relação Dsg1/Dsg3 correspondeu à mudança PV-PF. No grupo 2, o ES para EBA ocorreu sete anos após o diagnóstico de inicial de PF. No momento da suspeita de ES o paciente apresentava-se em remissão clínica do quadro de pênfigo folíaceo. A avaliação laboratorial mostrou clivagem subepidérmica neutrofílica, IFD com IgG intercelular intraepidérmica e depósitos de IgM, IgA, IgG e C3 na zona da membrana basal. IFI com técnica de salt split skin revelou depósitos de IgG do 
lado dérmico. Ao immunobloting houve reconhecimento de colágeno VII e ELISA para Dsg1 foi positivo. CONCLUSÃO: A frequência de ES em pacientes portadores de pênfigo foi de 2,6\%. Estudos serão necessários para elucidar a patogênese deste evento e sua importância na progressão dos pênfigos.

Descritores: 1.Epitopos/imunologia 2.Dermatopatias vesiculobolhosas 3.pênfigo 4.Epidermólise bolhosa adquirida 5.Imunofluorescência 6.Ensaio de imunoadsorção enzimática 


\section{ABSTRACT}

Delgado L. Epitope spreading" phenomena: clínical and immunopathological characterization in patients with bullous dermatosis (thesis). São Paulo: "Faculdade de Medicina, Universidade de São Paulo"; 2016. 64p.

BACKGROUND: Autoimmune bullous skin diseases represent a heterogeneous group of disorders of skin and mucosa associated with autoantibodies against distinct adhesion molecules. They can be classified, based on the level of loss of adhesion in intraepidermal and sub epidermal dermatosis. The shift from an autoimmune blistering disease to another has been recently described and attributed to the "epitope spreading" (ES) phenomena. It occurs when a primary inflammatory/autoimmune process releases "hidden" epitopes which are recognized by the lymphocytes and evoke a secondary reaction to antigens distinct from, and non-cross-reactive, with the disease causing-epitope. This study attempted to characterize the occurrence of ES in pemphigus patients. METHODS: We analyzed data from 351 pemphigus patients treated ambulatorially at the Department of Dermatology, Faculty of Medicine, University of São Paulo, from December 2002 to December 2012. A careful search for clinical and laboratorial (histopathology, direct-DIF and indirect-IIF immunofluorescence, ELISA) changes suggestive of shift to a secondary bullous disease was performed. RESULTS: Nine out of 351 patients presented clínical shift and were included in the study: eight from pemphigus vulgaris (PV) to foliaceus (PF) 2.3\% (group 1) and one from PF to epidermolysis bullosa acquisita (EBA) $0.3 \%$ (group 2). In group 1, median interval of disease shift was 3.5 years. Of 8 patients with clinical PF, five showed change of histopathology pattern from suprabasilar cleavage to subcorneal acantholysis, two had cleavage within the middle epidermal layer, and one sustained the suprabasilar acantholysis. One shifted back to PV after clinical and histopatological changes of PF. All patients showed intercellular lgG and/or C3 deposits during PV and PF diagnosis by DIF. IIF titers varied from 1:160 to 1:5120. ELISA index for Dsg1 varied from 22 to 319; and for Dsg3 from 0.4 to 224 (positive if >20). Dsg1/Dsg3 indexes corresponded to the clinical PV-PF changes. In group 2, onset of PF occurred at the age of 25, and ES to EBA 7 years later in the absence of PF lesions. Laboratory evaluation showed sub epidermal cleavage with neutrophils, IgG intercellular staining in the epidermis and $\lg M, \lg A, \lg G$ and $C 3$ deposits at BMZ by DIF, IgG deposits by indirect salt-split, recognition of collagen VII by immunoblotting, and positive ELISA for Dsg1. CONCLUSIONS: Intermolecular ES occurred in $2.6 \%(9 / 351)$ of pemphigus patients. Futures studies will be necessary to elucidate the pathogenesis of this event and its significance in pemphigus progression.

Descriptors: 1.Epitopes/immunology 2.Skin diseases, vesiculobullous 3.Pemphigus 4.Epidermolysis bullosa acquisita 5.Fluorescent antibody technique 6.Enzyme-linked immunosorbent assay 
1 INTRODUÇÃO 


\subsection{Dermatoses bolhosas autoimunes}

As dermatoses bolhosas autoimunes são doenças de alta morbidade caracterizadas pela formação de bolhas cutâneas e/ou mucosas, secundárias à produção de autoanticorpos contra antígenos epidérmicos ou da junção dermoepidérmica, relacionados à adesão epitelial ${ }^{(1)}$. Seu diagnóstico baseia-se no exame clínico associado ao exame histopatológico e de imunofluorescência, que podem ser completamentados por exames imunosorológicos (Enzymelinked immunosorbent assay-ELISA, Immunoblotting e imunoprecipitação) ${ }^{(1,2)}$.

A classificação destas dermatoses é realizada segundo o nível da clivagem à histopatologia (Figura 1) e correlaciona-se à localização dos epítopos alvos (epiderme ou zona da membrana basal); sendo divididas em dermatoses bolhosas intraepidérmicas e subepidérmicas. Clinicamente, as dermatoses intraepidérmicas caracterizam-se por bolhas flácidas e de fácil ruptura, enquanto nas dermatoses subepidérmicas as bolhas são tensas (Figura 2). 


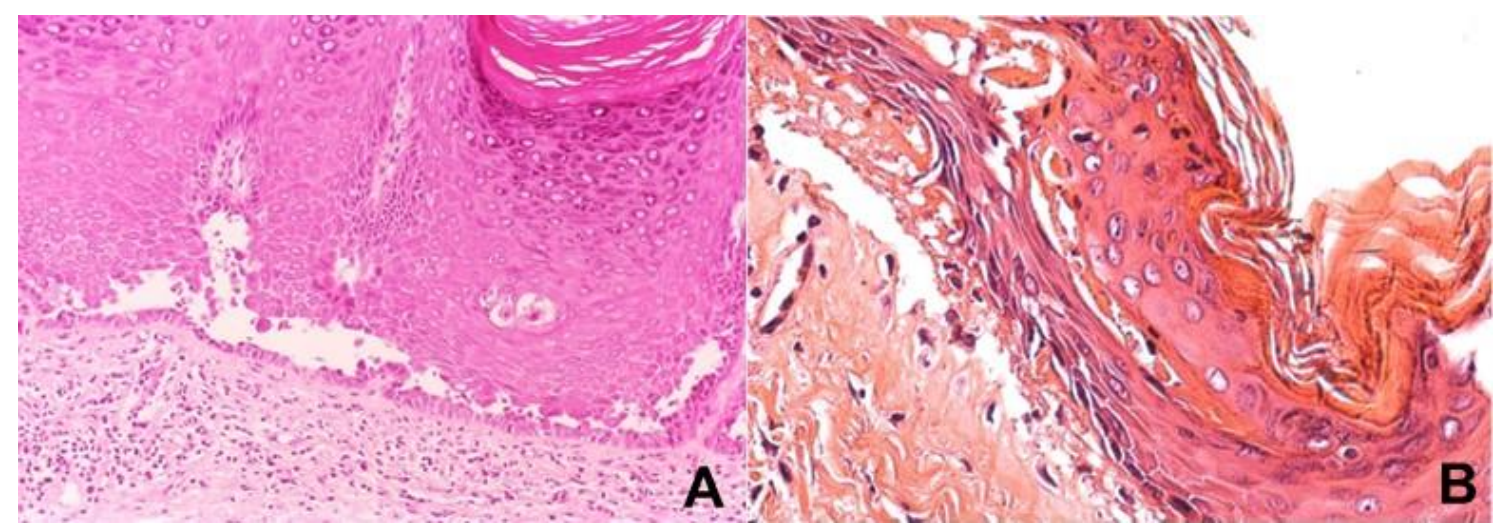

Figura 1. Histopatologia nas dermatoses bolhosas autoimunes. A. (HE. 10X) Dermatoses bolhosas intraepidérmicas: a clivagem ocorre na região epidérmica, neste exemplo nota-se clivagem acantolítica na camada suprabasal da epiderme; característica do pênfigo vulgar. B. (HE. 40X) Dermatoses bolhosas subepidérmicas: a clivagem ocorre na região subepidérmica. Neste exemplo, nota-se clivagem subepidérmica com infiltrado inflamatório de neutrófilos e eosinófilos em paciente com pênfigóide bolhoso

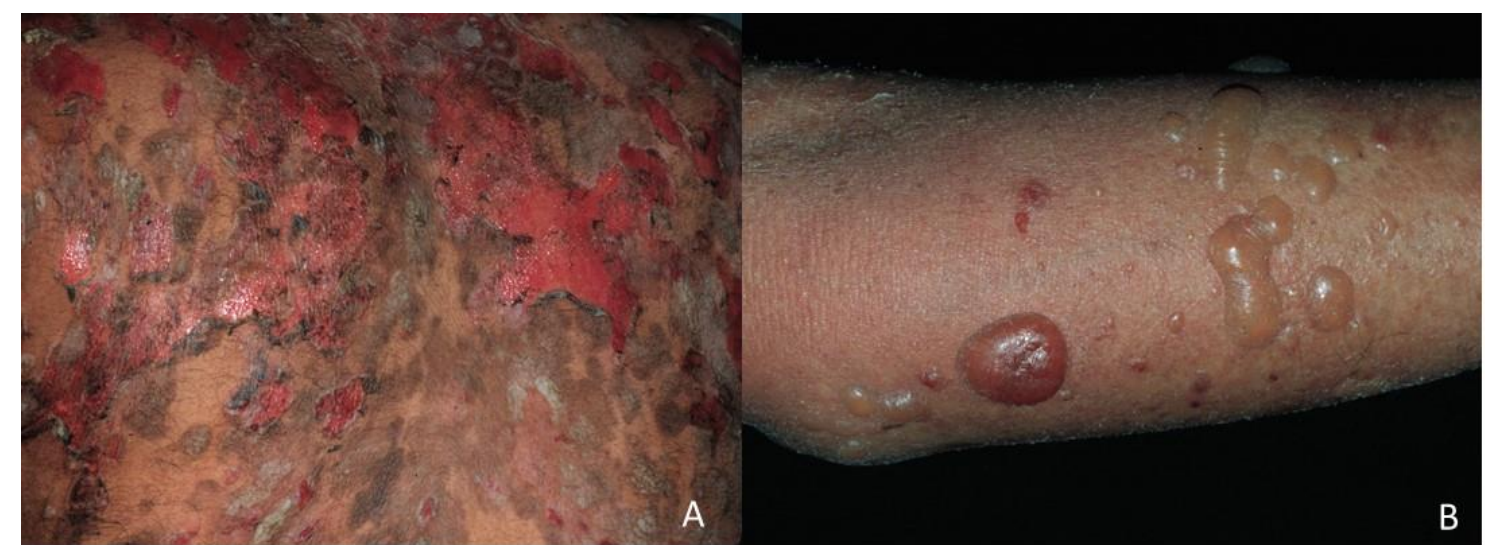

Figura 2. Aspecto clínico das lesões cutâneas nos diferentes grupos de dermatoses bolhosas autoimunes. A. Dermatoses bolhosas intraepidérmicas: devido à localização superficial da clivagem, ocorrem bolhas flácidas/erosões (paciente portador de pênfigo vulgar). B. Dermatoses bolhosas subepidérmicas: clinicamente notam-se bolhas tensas, por vezes com conteúdo hemorrágico (paciente portador de pênfigoíde bolhoso) 


\subsubsection{Dermatoses bolhosas intraepidérmicas}

Caracterizam-se pela presença de autoanticorpos dirigidos às proteínas dos desmossomos; estruturas responsáveis pela adesão intercelular em epitélios estratificados. A interferência na função desmossomal resulta em perda de adesão intercelular com consequente acantólise ${ }^{(3)}$ e formação de bolhas cutâneas e/ou mucosas flácidas e erosões.

A este grupo pertencem os pênfigos, representados principalmente pelos subtipos vulgar, foliáceo e foliáceo endêmico (Fogo Selvagem). Estes subtipos apresentam autoanticorpos dirigidos às desmogleínas; glicoproteínas desmossomais transmembrana dependentes de cálcio ${ }^{(4,5)}$.

As desmogleínas assim como as desmocolinas; pertencem a superfamília das caderinas, proteínas responsáveis pela integridade tissular. Tais proteínas apresentam uma porção extracelular, responsável pela adesão intercelular e uma porção intracelular, a qual interage com os filamentos intermediários de queratina no interior das células ${ }^{(6)}$ (Figura 3).

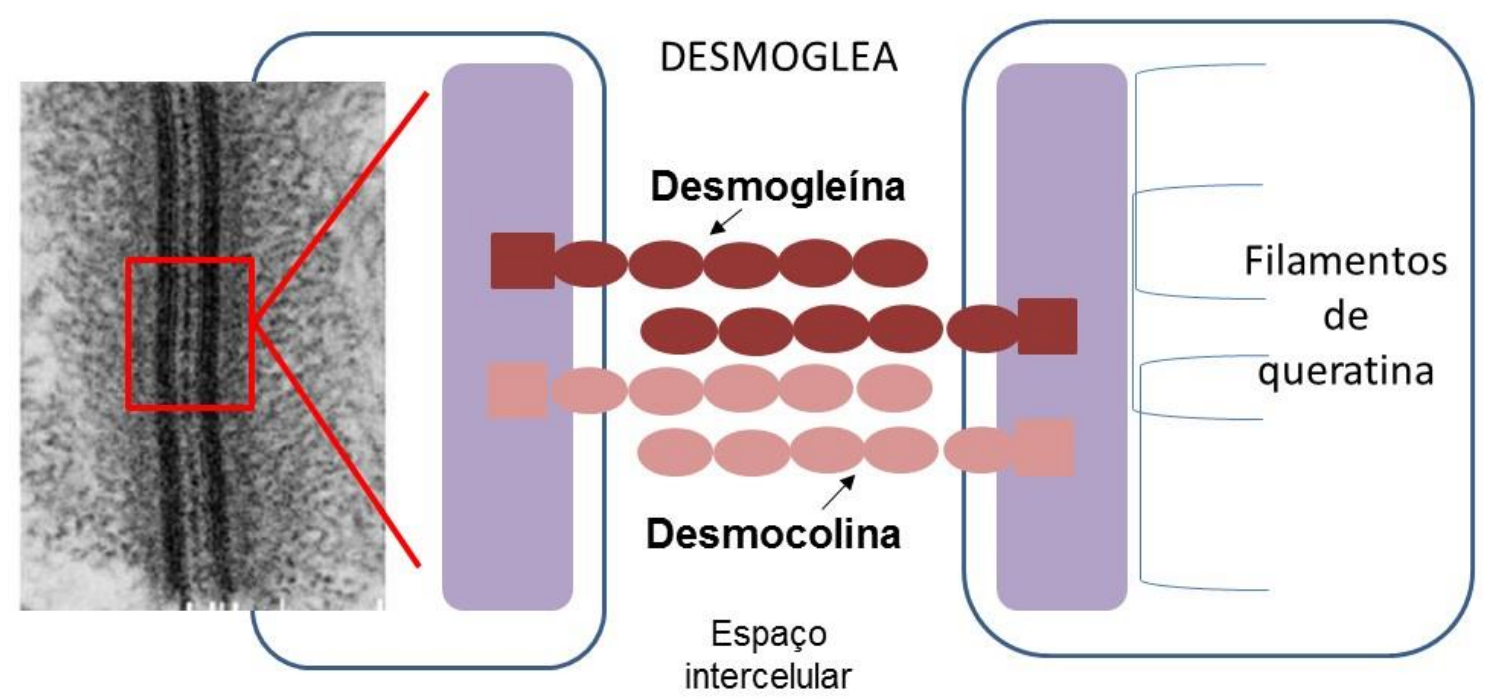

Figura 3. Composição dos desmossomos (Adaptado de Rook's Textbook of Dermatology, 2010, 8th Edition ${ }^{(7)}$ ) 
Existem 4 isoformas de desmogleínas (Dsg1-4), sendo a expressão das desmogleína 1 e 3 predominante nos epitélios estratificados ${ }^{(5)}$. A desmogleína 1 (160kDa) apresenta localização superficial na epiderme, enquanto a desmogleína 3 (130Kda) predomina em suas camadas inferiores. Nas superfícies mucosas, a distribuição da Dsg1 segue padrão semelhante ao da epiderme; enquanto a Dsg3 ocorre em toda a sua extensão (Figura 4).

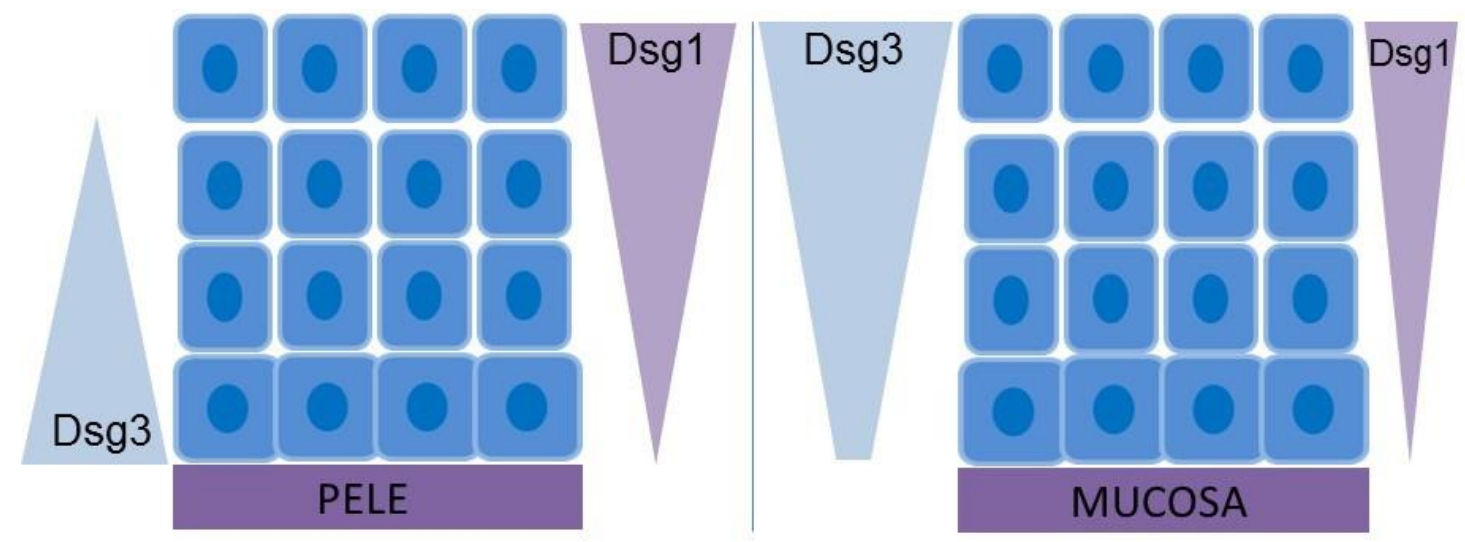

Figura 4. Distribuição de desmogleína 1 e 3 na pele e mucosas (Adaptado de Zillikens et $\mathrm{al}^{(8)}$ )

A desmogleína 1 é o alvo antigênico em pacientes portadores de pênfigo foliáceo e sua variante endêmica (Fogo Selvagem). Em pacientes portadores da forma cutâneo mucosa de pênfigo vulgar, os autoanticorpos são dirigidos à Dsg1 e 3, enquanto a forma exclusivamente mucosa apresenta autoanticorpos dirigidos apenas à Dsg3. Tal fato, correlaciona-se aos achados histopatológicos de tais dermatoses: a acantólise no pênfigo foliáceo ocorre na camada subcórnea (região onde predomina a expressão de Dsg1), enquanto no pênfigo vulgar ocorre na camada suprabasal (Figura 5). 


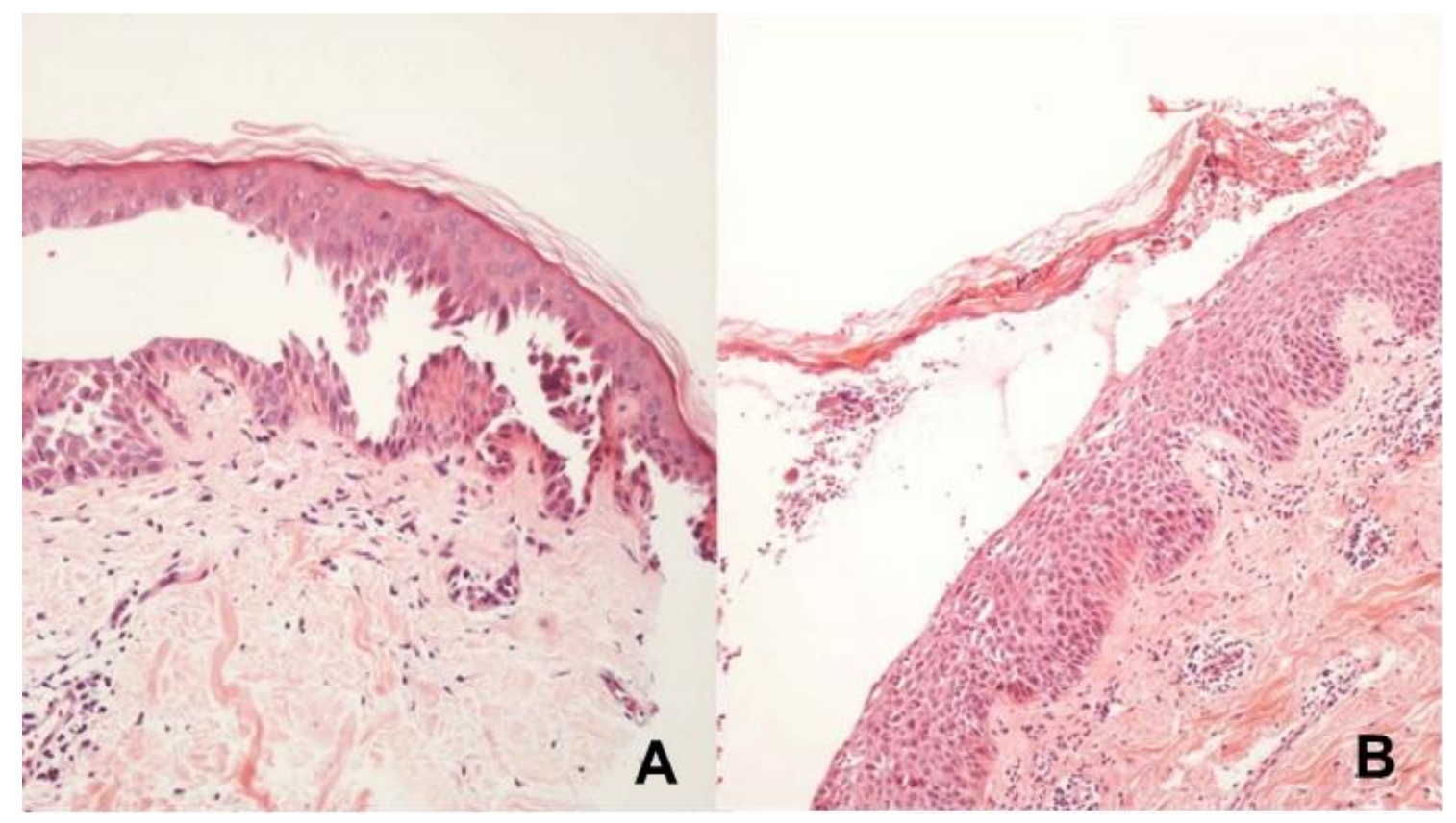

Figura 5. Histopatologia nos diferentes subtipos de pênfigo. A (HE. 40X): Pênfigo vulgar. Clivagem acantolítica na camada suprabasal da epiderme. B (HE. 10X): Pênfigo folíaceo. Clivagem acantolítica nas camadas superiores da epiderme (subcórnea).

Além disso, pacientes com pênfigo folíaceo apresentam lesões exclusivamente cutâneas, enquanto no pênfigo vulgar as lesões são cutaneomucosas ou exclusivamente mucosas. Esta diferente localização e distribuição das lesões bolhosas nos subtipos de pênfigo tem sido explicada através da teoria da compensação das desmogleínas. De acordo com esta teoria, ambas as desmogleínas (1 e 3) são responsáveis pela adesão desmossomal. Nas áreas em que ambas estão presentes, poderia haver compensação em caso de perda de função de algum subtipo ${ }^{(9)}$. Como exemplo têm-se a acantólise no pênfigo folíaceo: nas camadas superiores da epiderme há predomínio da desmogleína 1 e menor expressão de desmogleína 3. Como os anticorpos no PF dirigem-se à Dsg1, a perda desta desmogleína nas camadas inferiores da epiderme seria compensada pela presença de Dsg3 em 
grande quantidade e não ocorreria acantólise nesta região, já nas camadas superiores a quantidade de Dsg3 é insuficiente para compensar a perda da Dsg1 ocorrendo a clivagem acantolítica subcórnea típica desta dermatose. Nas mucosas a presença de Dsg3 em grande quantidade em toda sua extensão é suficiente para compensar a perda da Dsg1, o que explicaria a ausência de lesões mucosas nestes pacientes.

À imunofluorescência direta (IFD), ambas as formas de pênfigo apresentam depósitos lineares intercelulares intraepiteliais de C3 e lgG. A imunofluorescência indireta (IFI) revela depósitos intercelulares intraepiteliais às custas da subclasse lgG4 nos pacientes com doença ativa; lgG1 e IgG2 são detectados em títulos baixos nos pacientes em remissão. Os títulos de IFI apresentam correlação com direta com a atividade da doença ${ }^{(10)}$.

Ao ELISA detecta-se a presença de autoanticorpos antiDsg1 no PF, antiDsg3 na forma mucosa de PV, e à ambas as desmogleínas na forma cutâneo mucosa de PV. Os níveis de anticorpos antiDsg1 ao ELISA se correlacionam melhor com o curso da doença do que os níveis de anticorpo antiDsg $3^{(4)}$.

Os subtipos mais raros de pênfigos apresentam autoanticorpos dirigidos a proteínas desmossômicas e juncionais (exemplo: desmocolinas, plaquinas).

Os principais alvos antigênicos nas dermatoses bolhosas intraepidérmicas estão sumarizados no Quadro 1.

\subsubsection{Dermatoses bolhosas subepidérmicas}

Representadas principalmente pela epidermólise bolhosa adquirida (EBA), penfigóide bolhoso (PB), penfigóide das membranas mucosas (PMM), dermatose por IgA linear, dermatite herpetiforme (DH) e lúpus eritematoso bolhoso. 
Caracterizam-se pela produção de autoanticorpos dirigidos à um ou mais componentes da zona da membrana basal (ZMB) (Figura 6) seguido de ativação de complemento e formação de processo inflamatório ${ }^{(11,12)}$ com consequente clivagem subepidérmica.

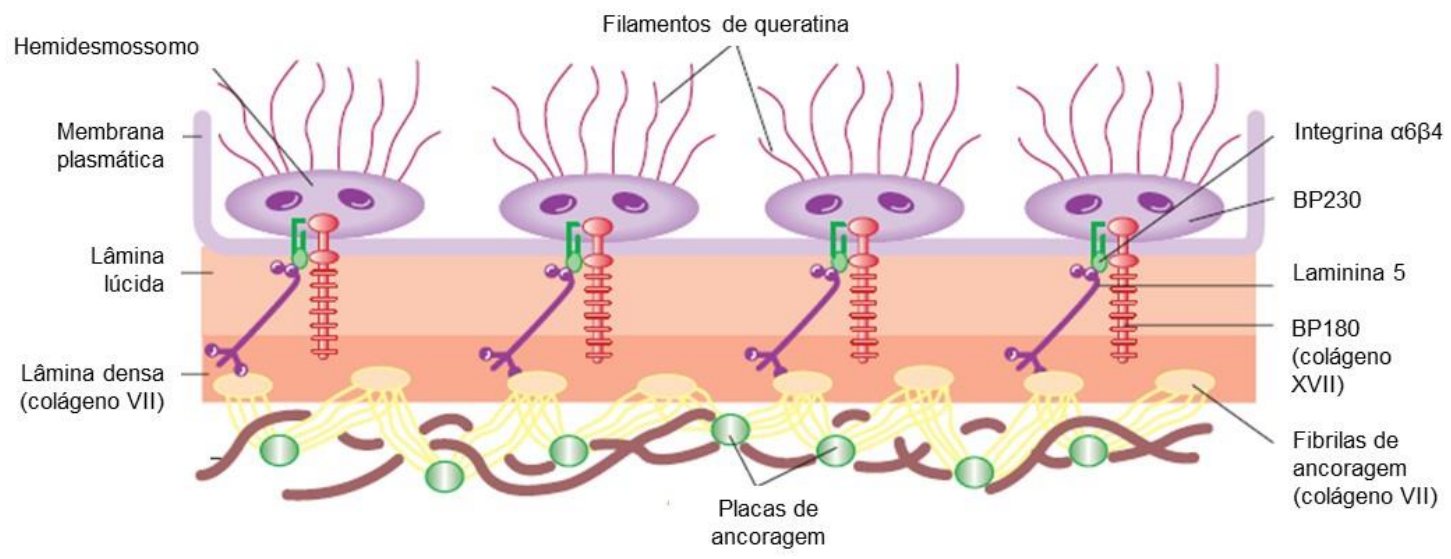

Figura 6. Representação esquemática da zona da membrana basal (Adaptado de Rook's Textbook of Dermatology, 2010, 8th Edition)

Os principais alvos antigênicos nas dermatoses subepidérmicas, localizam-se nas seguintes regiões ${ }^{(1,13)}$ :

\section{Hemidesmossomos e lâmina lúcida}

Moléculas responsáveis pela adesão dos queratinócitos basais com a derme superficial: antígenos como BP180 (BPAG2, colágeno XVII), BP230 (BPAG1) (alvos no penfigóide bolhoso e herpes gestacional), laminina $\mathrm{V}$ e a6ß4 integrina (penfigóide de membranas mucosas).

À histopatologia ocorre clivagem subepidérmica com infiltrado inflamatório eosinofílico no penfigóide bolhoso e misto com predomínio de mononucleares no penfigóide de membranas mucosas ${ }^{(2)}$. À IFD predominam 
depósitos lineares de IgG e C3 na zona da membrana basal. A IFI detecta anticorpos circulantes da classe lgG; além de depósitos do lado epidérmico da clivagem quando a técnica de salt split skin é utilizada ${ }^{(10)}$.

\section{Fibrilas de ancoragem}

Responsáveis pela adesão da dermo-epidérmica, apresenta como principal antígeno o colágeno VII (EBA e lúpus eritematoso bolhoso).

O exame histopatológico revela clivagem subepidérmica com infiltrado inflamatório variável ${ }^{(14)}$. À IFD ocorrem múltiplos depósitos lineares de lgG, IgA, C3 e IgM na ZMB; anticorpos anti-IgG na ZMB à IFI e depósitos no lado dérmico da clivagem ao salt split skin. Na EBA detectam-se anticorpos contra a porção NC1 do colágeno VII ao ELISA. As principais dermatoses bolhosas subepidérmicas e seus antígenos, são sumarizados no Quadro 1.

Quadro 1. Dermatoses bolhosas autoimunes e seus respectivos autoantígenos

\begin{tabular}{|c|c|}
\hline Dermatoses bolhosas intraepidérmicas & Autoantígeno \\
\hline Pênfigo foliáceo & Desmogleína 1 \\
\hline $\begin{array}{c}\text { Pênfigo vulgar, herpetiforme e induzido por } \\
\text { drogas }\end{array}$ & Desmogleína 3 e/ou Desmogleína 1 \\
\hline Pênfigo por lgA (tipo SPD) & Desmocolina 1 \\
\hline Pênfigo paraneoplásico & $\begin{array}{l}\text { Desmogleína 3, BP230, Desmoplaquinas } 1 \text { e } 2 \text {, } \\
\text { Envoplaquina, Periplaquina, Inibidor de protease, Alfa- } \\
\qquad 2 \text { macroglobulina-1 símile }\end{array}$ \\
\hline Dermatoses bolhosas subepidérmicas & Autoantígeno \\
\hline $\begin{array}{l}\text { Penfigoide bolhoso, Herpes gestacional, } \\
\text { Líquen Plano penfigóide }\end{array}$ & BP180 (Colágeno XVII), BP230 \\
\hline Penfigóide de membranas mucosas & $\begin{array}{c}\text { BP180 (Colágeno XVII ), BP230 } \\
\text { Laminina } 5 \text { e 6, a6134 integrina, Colágeno VII }\end{array}$ \\
\hline $\begin{array}{l}\text { Epidermólise bolhosa adquirida, Lúpus } \\
\text { eritematoso sistêmico bolhoso }\end{array}$ & Colágeno VII \\
\hline Dermatose bolhosa por IgA linear & $\begin{array}{c}\text { LAD-1 e LABD (produtos de clivagem do BP180), } \\
\text { Colágeno VII }\end{array}$ \\
\hline Dermatite herpetiforme & Transglutaminase 3 \\
\hline
\end{tabular}

Legenda: SPD: Dermatose pustular subcórnea. FONTE: adaptado de Kneisel et al. $2011^{(2)}$ 


\subsection{Papel do epitope spreading em doenças autoimunes}

O fenômeno de epitope spreading tem sido investigado em diversas patologias autoimunes manifestando-se como a coexistência de autoanticorpos dirigidos a diferentes antígenos em um mesmo paciente, ou a transformação de seu quadro clínico e laboratorial com progressão para doença autoimune ou inflamatória secundária, distinta da inicial. Tais achados tem sido descritos na literatura e ocorrem em diversas patologias autoimunes: como diabetes, lúpus eritematoso sistêmico, esclerose múltipla e dermatoses bolhosas adquiridas ${ }^{(15)}$. Inicialmente, entre as teorias para explicar tais fenômenos encontrava-se a de uma possível susceptibilidade genética ao desenvolvimento de doenças autoimunes $^{(16)}$.

Posteriormente, através de estudos experimentais em modelos animais; principalmente em encefalomielite autoimune ${ }^{(17,18)}$, houve a descrição do fenômeno de epitope spreading (ES) e sua implicação na progressão e patogênese de inúmeras patologias autoimunes ${ }^{(15,16,19,20)}$.

Tal fenômeno ocorreria quando o processo inflamatório ou autoimune primário, ao causar lesão tissular, exporia certos antígenos antes desconhecidos ao sistema imune, elicitando uma resposta imune de células $T$ e B secundária contra antígenos diferentes e não relacionados aos originais ${ }^{(20)}$.

Quando o epitope spreading ocorre na mesma molécula (diferentes epítopos do mesmo antígeno), temos o epitope spreading intramolecular; se em moléculas antigênicas diferentes o epitope spreading denomina-se intermolecular. Além disso, o epitope spreading pode ser mediado por linfócitos B ou $\mathrm{T}^{(16,21)}$. 
No epitope spreading de linfócitos T (LT) a apresentação de um epítopo primário aos linfócitos T helper (LTh) levaria a uma injúria tecidual decorrente da resposta inflamatória, com surgimento de novo antígeno secundário ou de um segundo epítopo no mesmo antígeno. Os LTh naive, em contato com esse segundo epítopo, induziriam o desenvolvimento de autoimunidade celular ou humoral direcionada contra o segundo antígeno (ou epítopo) ${ }^{(16)}$ (Figura 7).

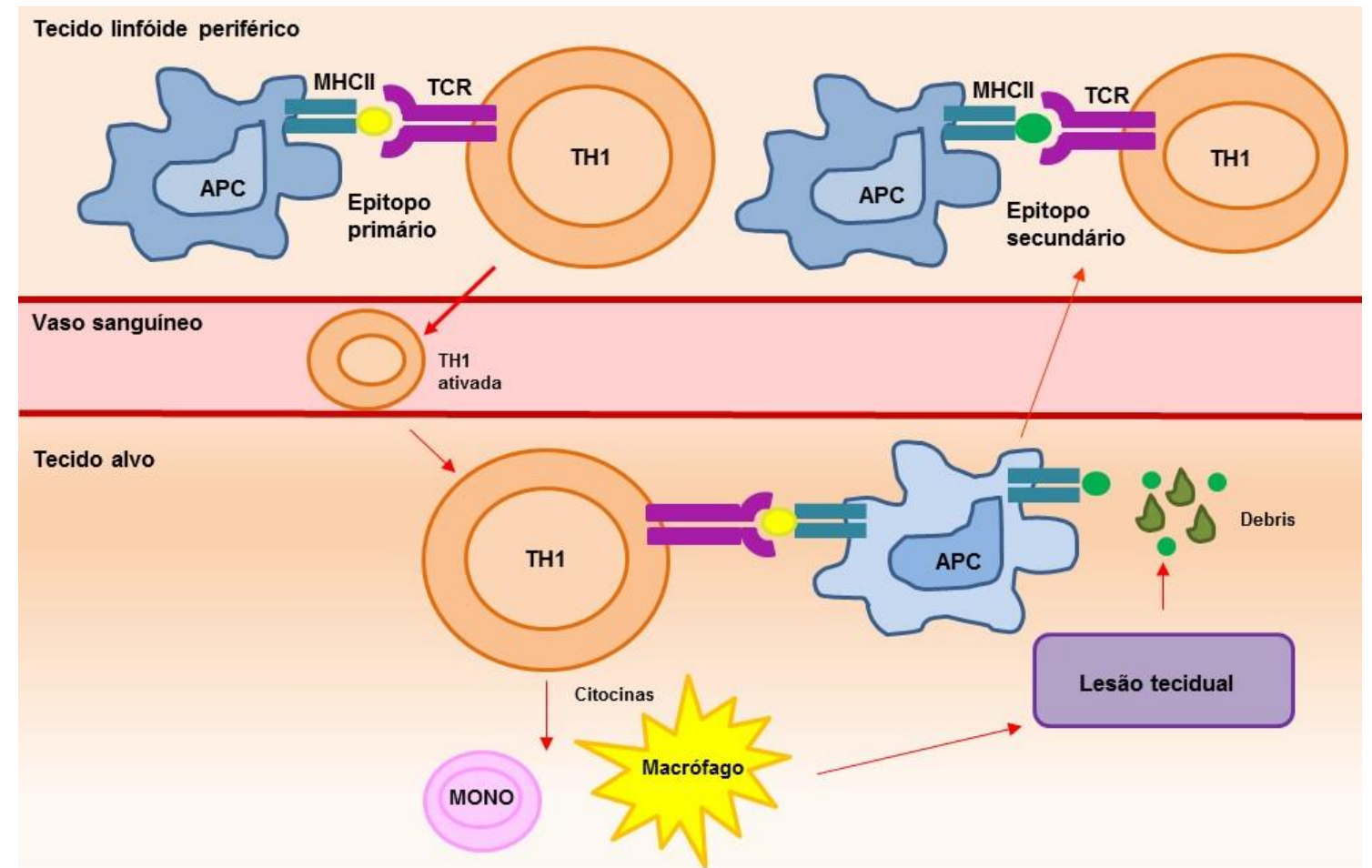

Adaptado de Vanderlugt et al(20)

Figura 7. Epitope spreading de linfócitos T. A apresentação do epitopo primário ocorre no tecido linfóide periférico e resulta em diferenciação e ativação dos linfócitos $T$, com recrutamento de macrófagos e monócitos, os quais produzem espécies reativas de oxigênio e TNF-alfa resultando em lesão tecidual. Os debris resultantes da lesão tecidual podem ser processados pelas células apresentadoras de antígenos residentes e periféricas levando a ativação de uma nova leva de linfócitos T reativos ao epítopo secundário 
Já no ES de linfócitos B (LB), a especificidade do LB ao antígeno da doença inicial poderia progredir para a inclusão de outros epítopos deste mesmo antígeno ou de novos antígenos; através da interação com linfócitos T, do processamento endocítico de antígenos e de mutação hipersomática ${ }^{(15)}$ :

\section{Interação com células T}

Os antígenos de diversas doenças autoimunes são parte de complexos multiantigênicos; linfócitos $\mathrm{T}$ específicos para epítopos destes complexos podem ativar linfócitos B específicos para outros antígenos. Assim os linfócitos T poderiam ajudar os linfócitos B a proliferar, diferenciar e produzir anticorpos contra epítopos não originalmente envolvidos na resposta imune.

\section{Processamento endocítico}

Durante o processamento endocítico o antígeno sofre endocitose, é seletivamente clivado e então apresentado na superfície da célula através do complexo MHCII. Este processo poderia permitir a apresentação, via moléculas MHCII, de antígenos previamente não reconhecidos pelo sistema imune e expansão da resposta imune para inclusão de novos epítopos da molécula que sofreu endocitose.

\section{Mutação hipersomática}

Nos tecidos linfóides, após a ativação dos linfócitos $B$ em resposta a um antígeno, linfócitos B filhos são produzidos através de expansão clonal. Estas células filhas induzem modificações nas regiões variáveis no gene da 
imunoglobulina processo que permite a seleção de linfócitos B com maior afinidade ao antígeno. Fenômenos de ES poderiam ocorrer caso houvesse a seleção de linfócitos B dirigidos a antígenos diferentes do inicial.

Outros fatores que podem contribuir para o desenvolvimento de fenômenos de epitope spreading incluem o mimetismo molecular e a reatividade cruzada. O mimetismo molecular ocorre quando um autoantígeno é similar o suficiente a um antígeno patogênico ou ambiental para levar à produção de anticorpos contra o antígeno patogênico e contra o autoantígeno ${ }^{(6,15,22)}$. As reações cruzadas ocorrem quando um anticorpo reage a múltiplos antígenos que variam em estrutura e composição ${ }^{(23)}$.

Acredita-se que ambos processos participem do desenvolvimento da forma endêmica de PF: nas regiões endêmicas, insetos hematófogos poderiam desencadear a doença ao possuir uma molécula indutora da produção de autoanticorpos antiDsg1 através de mimetismo molecular e reações $\operatorname{cruzadas}^{(24)}$. 
2 REVISÃO DA LITERATURA 
Epitope spreading e dermatoses bolhosas autoimunes

\subsection{Epitope spreading intramolecular}

\section{Pênfigo foliáceo}

Fenômenos de epitope spreading intramolecular são responsáveis pela transição de um estágio pré-clínico para clínico em pacientes portadores de pênfigo foliáceo endêmico( ${ }^{(24,25)}$.

A molécula de Dsg1 apresenta um ectodomínio subdividido em 5 domínios (EC1 a EC5), os primeiros 4 domínios são sítios de ligação de cálcio e o quinto é uma região curta, proximal à membrana celular sem homologia com outras regiões das caderinas. No estágio pré-clínico da doença os pacientes apresentam anticorpos do tipo lgG1 contra o domínio EC5; provavelmente desencadeados por estimulo ambiental (relacionado à presença de insetos hematófagos nas áreas endêmicas) em um indivíduo susceptível (HLADRB1 é o mais relacionado). Após o fenômeno de epitope spreading, ocorreria transição do perfil de autoanticorpos (produção de anticorpos do tipo IgG4 contra os domínios EC1 e EC2) $)^{(21,24)}$ (Figura 8). 


\section{Desmogleína 1}
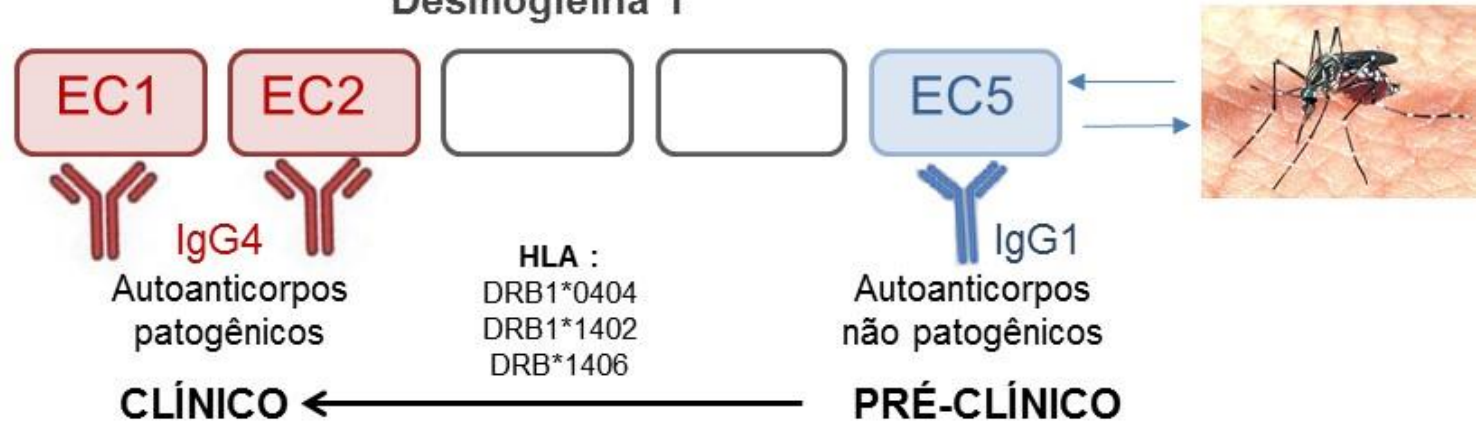

Autoanticorpos não patogênicos

PRÉ-CLÍNICO

Adaptado de Aoki et al(24)

Figura 8. Epitope spreading intramolecular no pênfigo folíaceo endêmico. A transição de um estágio pré-clínico para clínico em pacientes portadores de pênfigo foliáceo endêmico ocorre após modificação do epítopo alvo

\section{Pênfigo vulgar mucoso para pênfigo vulgar cutâneo mucoso}

No pênfigo vulgar, pacientes com lesões confinadas às mucosas (devido a autoanticorpos patogênicos antiDsg3) podem, gradualmente, progredir com acometimento cutâneo mucoso (autoanticorpos dirigidos à Dsg1 e 3) ${ }^{(16,21)}$. Portanto, o epitope spreading ocorre em pacientes cuja doença progride da forma mucosa para a cutâneo mucosa. Salato et $\mathrm{al}^{(26)}$, investigaram $\mathrm{o}$ mecanismo de tal transição através do estudo dos epítopos da Dsg3 em pacientes com PV mucoso que apresentaram transição para a forma cutâneo mucosa. Eles demonstraram que após a transição; os autoanticorpos reconhecem diferentes epítopos na molécula de Dsg3. De acordo com os autores, este ES intramolecular é passo importante e precede o ES intermolecular de Dsg3 à Dsg1. 


\subsection{Epitope spreading intermolecular}

\section{Conversão de pênfigo vulgar para pênfigo foliáceo}

$\mathrm{Na}$ literatura, existem até o momento vinte e três relatos de desenvolvimento de quadro clínico e laboratorial de pênfigo foliáceo em pacientes com diagnóstico prévio de pênfigo vulgar (autores e dados sumarizados na Tabela 1); acredita-se que tal conversão implique em melhor prognóstico ${ }^{(27-40)}$.

\section{Conversão de pênfigo foliáceo para pênfigo vulgar}

Descrito com menor frequência que o fenômeno anterior; com cinco casos publicados na literatura ${ }^{(36,41-44)}$ (Tabela 1).

\section{Conversão de pênfigo foliáceo para penfigóide bolhoso}

A transição de uma doença bolhosa subepidérmica para epidérmica ou vice-versa, é fenômeno ainda mais raro, porém a transição de $\mathrm{PF}$ para $\mathrm{PB}^{(45-47)}$ já foi relatada (Tabela 1). 
Tabela 1. Revisão da literatura: Epitope spreading intermolecular em pacientes portadores de pênfigo

\begin{tabular}{|c|c|c|c|}
\hline \multicolumn{4}{|c|}{ ES INTERMOLECULAR EM PACIENTES COM PÊNFIGO } \\
\hline ES & $\mathbf{N}^{\circ}$ casos & Tempo para ES & Autor. Ano \\
\hline \multirow{14}{*}{$\begin{array}{l}\text { PV a PF } \\
(n=23)\end{array}$} & 3 & $3-20 a$ & Hashimoto.1991 \\
\hline & 2 & $1-3 a$ & Iwatsuki.1991 \\
\hline & 2 & $3 a$ & Kawana.1994 \\
\hline & 1 & $1 \mathrm{a}$ & Chorzelski.1995 \\
\hline & 1 & $3 a$ & Chang.1997 \\
\hline & 1 & - & Mendiratta.2000 \\
\hline & 3 & $6 m-1 a$ & Komai.2001 \\
\hline & 1 & $5 a$ & Kimoto.2001 \\
\hline & 1 & $2 a$ & Tsuji. 2002 \\
\hline & 1 & $5 a$ & Harman. 2002 \\
\hline & 1 & $2 a$ & Toth. 2002 \\
\hline & 3 & $2-4 a$ & Ng. 2005 \\
\hline & 2 & 2-4 a. & Espana 2014 \\
\hline & 1 & $2,5 \mathrm{~m}$ & Ito, 2014 \\
\hline \multirow{5}{*}{$\begin{array}{l}\text { PF a PV } \\
(n=5)\end{array}$} & 1 & $6 a$ & Ishii.2000 \\
\hline & 1 & $6 m$ & Komai.2001 \\
\hline & 1 & $5 a$ & Park. 2006 \\
\hline & 1 & $1 a$ & Pigozzi.2007 \\
\hline & 1 & $1-10 m$ & Awazawa.2007 \\
\hline \multirow{3}{*}{$\begin{array}{l}\text { PF a PB } \\
(n=3)\end{array}$} & 1 & $3,5 a$ & Peterson.1994 \\
\hline & 1 & $12 \mathrm{a}$ & Maeda. 2006 \\
\hline & 1 & $23 a$ & Recke.2009 \\
\hline
\end{tabular}

Legendas: n. Número de casos. a. Anos para a transição clínica. m. meses 


\subsection{Epitope spreading com coexistência de achados moleculares de diferentes dermatoses autoimunes}

\section{Penfigóide bolhoso e pênfigos}

A coexistência de penfigóide bolhoso com subtipos de pênfigo tem sido descrita por diversos autores ${ }^{(48-51)}$.

Zakka et $\mathrm{al}^{(52)}$ em estudo com 15 pacientes portadores de PV detectou, após um período médio de 80 meses, a presença ao ELISA de autoanticorpos anti BP180 (característicos de PB) em todos os pacientes. Além disso, o ELISA foi positivo para Dsg1 em 7 pacientes e para Dsg3 em 15. Estes pacientes apresentavam quadro refratário e crônico não responsivo à terapia tradicional.

\section{Penfigóide de membranas mucosas e pênfigo vulgar}

A coexistência de autoanticorpos causadores de Penfigóide de membranas mucosas (PMM) e pênfigo também é descrita ${ }^{(52,53)}$. Sami et al ${ }^{(54)}$ em estudo com 15 pacientes com diagnóstico clínico e laboratorial inicial de PMM detectou, após período de 7,2 anos, anticorpos patogênicos contra a Dsg3 (PV) além de positividade à $\beta 4$ integrina (PMM) ao imunobloting.

\section{Penfigóide bolhoso e epidermólise bolhosa adquirida}

Fairley et $a^{(55)}$ descreveram caso de paciente com penfigóide bolhoso com evolução clínica sugestiva de epidermólise bolhosa adquirida após 9 anos. Durante este período o paciente que inicialmente apresentava apenas positividade ao antígeno BP180 ao ELISA, desenvolveu autoanticorpos contra colágeno VII. 


\section{Herpes gestacional e epidermólise bolhosa adquirida}

Yang et $\mathrm{al}^{(56)}$ relataram caso de primigrávida que desenvolveu erupção vesicobolhosa as 26 semanas de gestação. Os exames histopatológico e de imunofluorescência foram sugestivos do diagnóstico de Herpes gestacional. No entanto, ao Immunoblotting a paciente apresentava reatividade, além de BP180 e BP230, ao colágeno VII.

\subsection{Epitope spreading e coexistência de doenças autoimunes e inflamatórias}

Diversos relatos de associação de doenças inflamatórias e autoimunes tem sido publicados e atribuídos a fenômenos de epitope spreading. Exemplos incluem desenvolvimento de PB após diagnóstico de psoríase ${ }^{(57) ;}$ PMM após quadro de síndrome de Steven Johnson ${ }^{(58)}$; doença de Crohn associada à EBA ${ }^{(59)}$ (aproximadamente 35 casos na literatura) e retocolite ulcerativa ${ }^{(59)}$ (aproximadamente 7 relatos) e retocolite ulcerative associada à dermatose por $\lg \mathrm{A}$ linear ${ }^{(60)}$ ou $\mathrm{PB}^{(61)}$. 
3 OBJETIVOS 


\subsection{Gerais}

O presente estudo tem por objetivo avaliar a frequência de fenômenos de epitope spreading intermolecular antigos ou em evolução entre pacientes portadores de pênfigos.

\subsection{Específicos}

- Comparar as fases pré e pós epitope spreading quanto a achados do exame histopatológico (nível da clivagem), de imunofluorescência (IFD, IFI) e títulos de anticorpos antiDsg1 e antiDsg3.

- Correlacionar índices de Dsg1/Dsg3 com conversão clínica devido ao fenômeno de epitope spreading. 
4 CASUÍSTICA E MÉTODOS 


\subsection{Casuística}

\subsubsection{Critérios de inclusão}

\section{Seleção dos Pacientes}

Foram incluídos pacientes maiores de 18 anos, portadores de pênfigos que apresentaram modificação clínico-laboratorial de sua doença primária com sinais clínicos sugestivos de conversão para uma segunda doença bolhosa autoimune.

Os pacientes foram selecionados através de revisão minuciosa de prontuários dos indivíduos acompanhados no Ambulatório de Dermatoses Bolhosas Autoimunes do Departamento de Dermatologia do Hospital das Clínicas da Faculdade de Medicina da Universidade de São Paulo (HCFMUSP) a partir de 2002, além de avaliação e seguimento de pacientes atuais. O período do estudo foi compreendido entre dezembro de 2002 a dezembro de 2012.

Os pacientes foram informados sobre o estudo e terão o sigilo de seus dados garantido, de acordo com a declaração de confidencialidade aprovada pelo Comitê de Ética em Pesquisa (CAPPesq) do HCFMUSP (número do parecer:0568/11) (Anexos 1 e 2). 


\subsubsection{Critérios de exclusão}

Excluíram-se os pacientes que não apresentavam quadro clínico/laboratorial sugestivo de fenômenos de epitope spreading nos registros dos prontuários médicos ou durante acompanhamento.

\subsection{Avaliação dos indivíduos}

\subsubsection{Avaliação clínica}

Exame clínico realizado por pelo menos dois dermatologistas e coleta de dados epidemiológicos e clínicos.

\subsubsection{Avaliação histopatológica}

Nos pacientes com quadro sugestivo de ES atual, foram obtidos fragmentos de pele lesional a partir de biópsias por punch $4 \mathrm{~mm}$. A avaliação histopatológica de tais fragmentos foi realizada através da coloração de hematoxilina eosina (HE). Além disso, revisou-se laudos de biópsias de exames histopatológicos prévios de todos os pacientes incluídos. 


\subsubsection{Avaliação de imunofluorescência e imunosorológica}

\section{Imunofluorescência direta (IFD)}

Biópsias por punch foram coletadas em área perilesional, e submetidas ao processo descrito a seguir:

A amostra recebeu conjugado anti-imunoglobulina humana produzida em animal imunizado e associada a um fluorocromo (conjugado FITC, Sigma Aldrich, USA) diluído em Azul de Evans (1:30). Os conjugados utilizados foram: anti-lgG, anti-lgA, anti-IgM e anti-C3 (Sigma Aldrich, USA). A leitura foi realizada em microscópio de fluorescência (Zeiss, Alemanha). O resultado foi dado em padrão (linear, homogêneo) e localização da fluorescência (ZMB ou epiderme) (Figura 9).

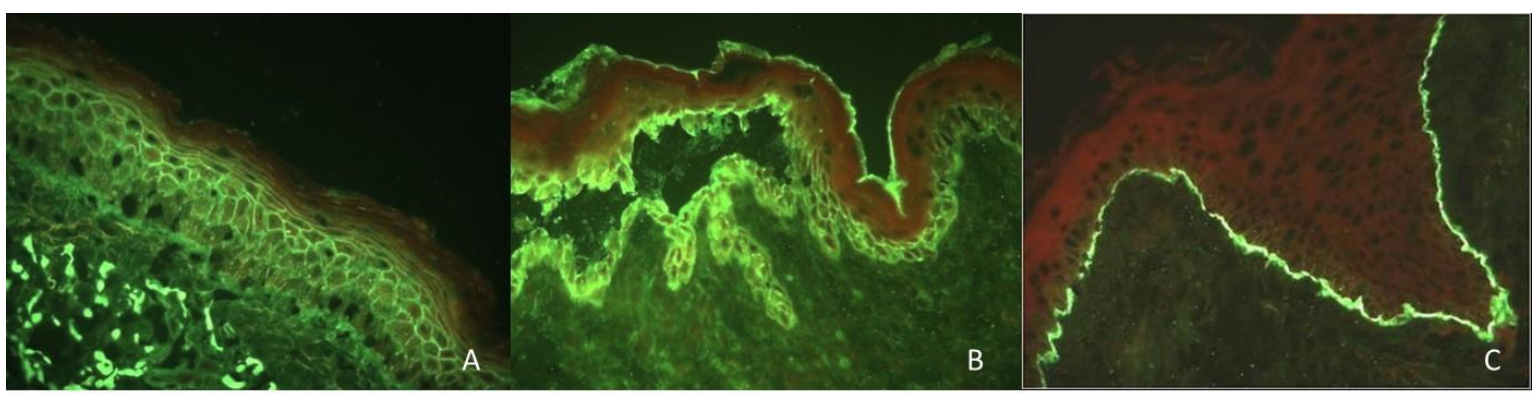

Figura 9. Padrões de imunofluorescência direta: A: fluorescência intercelular intraepidérmica, paciente com diagnóstico de pênfigo foliáceo. B. Fluorescência intercelular intraepidérmica com predomínio nas camadas inferiores da epiderme, característico de pênfigo vulgar. C: depósitos lineares na ZMB (penfigóide bolhoso) 


\section{Imunofluorescência Indireta (IgG total)}

Os soros dos pacientes, armazenados a $-70^{\circ} \mathrm{C}$ foram testados em substrato de pele normal humana (prepúcio). O substrato foi cortado em fragmentos de 4 micrometros e incubado por 60 minutos com diluições séricas a partir de 1:1520. As lâminas foram lavadas com solução salina Tris-buffered saline (TBS) duas vezes por 20 minutos cada e então cobertas com conjugado fluoresceína-tiocianato (FITC) com lgG anti-humana na diluição de 1530 (Sigma, USA) por 30 minutos. Após duas lavagens adicionais de 20 minutos com TBS, as lâminas foram montadas em glicerol e examinadas no microscópio de fluorescência (Zeiss, Alemanha). O resultado foi dado em padrão (linear, homogêneo) e localização da fluorescência (ZMB ou epiderme).

\section{Imunofluorescência indireta com técnica de Salt split skin}

Em pacientes selecionados, com suspeita de dermatoses bolhosas subepidérmicas, esta técnica foi empregada. Para sua realização, o substrato de pele normal foi incubado em solução de cloreto de sódio a 1.0M ( $\mathrm{NaCl} 1.0 \mathrm{M})$ a $4^{\circ} \mathrm{C}$ por $72 \mathrm{~h}$, com troca diária da solução. Posteriormente este substrato foi gentilmente tracionado com uma pinça até que ocorresse a separação (split) na lâmina lúcida da membrana basal. Os fragmentos foram então processados da mesma maneira descrita acima (para a técnica de IFI).

\section{Análise do soro dos pacientes por ELISA}

Técnica de ELISA com desmogleínas 1 e 3 recombinantes

Os soros dos pacientes selecionados foram avaliados através da técnica 
de ELISA (enzyme linked immunosorbent assay), conforme o protocolo recomendado pelo fabricante (MBL, Mesacup, Japan), para os anticorpos anti Dsg1 e anti Dsg3. As análises foram realizadas nas amostras de soro armazenadas $\mathrm{a}-70^{\circ} \mathrm{C}$. Duas amostras de pacientes com PF e PV confirmados foram utilizados como controles positivos para Dsg1 e Dsg 3 respectivamente.

Os soros obtidos foram diluídos, homogeneizados e incubados na placa de ELISA. Após incubação por 1 hora, foi feita a lavagem automatizada por 4 vezes, com tampão de lavagem do kit ELISA. Em seguida, foram incubados com o conjugado (anticorpo monoclonal murino anti-humano conjugado à horse-radish-peroxidase-HRP) por uma hora. Nova lavagem automatizada por 4 vezes com tampão foi realizada e após aplicou-se substrato tetrametilbenzidina/peróxido de hidrogênio: TMB/H2O2) seguido de solução bloqueadora (0,1 M ácido sulfúrico). Finalmente, realizou-se a leitura no espectrofotômetro (comprimento de onda: $450 \mathrm{~nm}$ ).

Interpretação dos resultados:

Cálculo dos resultados:

Valor $(\mathrm{U} / \mathrm{ml})=(\mathrm{A} 450$ amostra $-\mathrm{A} 450$ calibrador negativo $) \quad \mathrm{x} 100$ (A450Dsg calibrador - A450 calibrador negativo)

A450: valor de absorbância a 450nm 
A análise dos resultados foi feita a partir dos parâmetros do fabricante (Quadro 2).

Quadro 2. Interpretação dos resultados de ELISA

\begin{tabular}{|c|c|}
\hline Desmogleína 1 & Desmogleína 3 \\
\hline$<14$ Negativo & $<14$ Negativo \\
\hline $14-20$ Duvidoso & $14-20$ Duvidoso \\
\hline$>20$ Positivo & $>20$ Positivo \\
\hline
\end{tabular}

FONTE: (MBL, Mesacup, Japan)

\section{Avaliação do soro dos pacientes por Immunoblotting}

O soro de paciente selecionado com suspeita de quadro sugestivo de EBA, armazenado a $-70^{\circ} \mathrm{C}$, foi analisado através de Immunoblotting para colágeno VII.

A eficiência da transferência das frações proteícas e a localização das proteínas do padrão de PM, nas membranas de nitrocelulose, foi realizada com o corante Ponceau (Ponceau-S, 0,2\%, ácido acético 1\%). A região correspondente ao marcador do PM (protein mix), corada com o Ponceau, foi localizada nas membranas, recortada e corada posteriormente com Amido black $0,1 \%$. Após 20 segundos foi descorada com ácido acético 7\%. A membrana restante corada com Ponceau foi descorada com PBS (phosphate buffered saline). Posteriormente a membrana foi bloqueada com uma solução bloqueadora (leite desnatado a 5\%, Molico-Nestlé®) diluída em PBS, por 1 hora, a temperatura ambiente sob agitação constante. A membrana bloqueada 
foi incubada com os soros diluídos em PBS contendo $1 \%$ de leite, por 2 horas, à temperatura ambiente, sob agitação constante. Após 5 lavagens (5 minutos) com PBS, a membrana foi incubada com anticorpo anti-lgG humano conjugado à peroxidase (Sigma Co.) diluídos 1:4.000 em PBS contendo 1\% de leite, por 2 horas a temperatura ambiente sob agitação. Após novo ciclo de lavagens em PBS, os imunocomplexos foram visualizados, por meio da adição de $500 \mu \mathrm{l}$ de uma solução reveladora (6mg de 4-Cloro-naftol; 2ml de Metanol; 10ml de PBS e $10 \mu \mathrm{l}$ de $\mathrm{H}_{2} \mathrm{O}_{2}$ ). A reação foi interrompida por adição de água destilada, após o aparecimento das bandas. A membrana foi então lavada em água destilada e seca entre dois papéis de filtro. A documentação foi realizada por fotografias ou digitalizadas por um programa de computador. 
5 RESULTADOS 


\subsection{Variáveis demográficas e clínicas}

Dados de 495 pacientes foram inicialmente revistos. Destes 351 eram portadores de pênfigos (153 pênfigo folíaceo e 198 pênfigo vulgar) e o restante portadores de outras dermatoses bolhosas autoimunes. Nos pacientes portadores de outras dermatoses não foram notados sinais clínicos de fenômenos de epitope spreading. Entre os pacientes com pênfigos, nove apresentaram quadro clínico sugestivo de fenômeno de epitope spreading e foram incluídos no estudo, sendo oito com conversão clínica de PV para PF (grupo 1) e um de PF para epidermólise bolhosa adquirida (grupo 2).

\subsubsection{Variáveis demográficas e clínicas: Grupo 1}

No primeiro grupo a mediana de idade ao início da primeira dermatose foi de 54,5 anos (de 34 a 70 anos) e a mediana do intervalo entre o diagnóstico de PV e sinais clínicos de epitope spreading foi de 3,5 anos (2 a 7 anos). A maioria dos pacientes era caucasiana (5 de 8 , sendo 1 de origem italiana), um apresentava ascendência oriental e dois eram afrodescendentes.

Doenças concomitantes incluíram diabetes mellitus (2 pacientes), hipertensão arterial (4 pacientes), hipotireoidismo e dislipidemia (1 paciente) e adenocarcinoma de cólon bem diferenciado (1 paciente) 
O quadro clínico caracterizou-se por remissões e recidivas em uso de corticoterapia (prednisona de 0,5 a $1 \mathrm{mg} / \mathrm{kg} / \mathrm{dia}$, tratamento inicial em todos os pacientes) associada a azatioprina (50 a 100mg/dia) ou micofenolato de mofetila (3g/dia). Inicialmente, todos os pacientes apresentavam lesões cutaneomucosas no momento do diagnóstico de pênfigo vulgar. No momento de suspeita de fenômeno de epitope spreading as lesões eram apenas cutâneas, superficiais e crostosas com distribuição predominante no tronco, couro cabeludo e membros. Ao término do estudo quatro pacientes apresentavam remissão clínica (dois com doses baixas de prednisona e dois sem uso de imunosupressores). As variáveis demográficas e clínicas dos pacientes do grupo 1, estão sumarizados na Tabela 2. 
Tabela 2. Variáveis demográficas e clínicas dos pacientes do grupo 1 (PV a PF)

\begin{tabular}{|c|c|c|c|c|c|}
\hline Procedência & $\begin{array}{l}\text { Idade } \\
\left(1^{\circ}\right. \\
\text { Dx })\end{array}$ & Cor & Comorbidades & Tratamentos & $\begin{array}{l}\text { Evolução ao } \\
\text { término } \\
\text { estudo }\end{array}$ \\
\hline São Paulo & 36 & Afrodescendente & Dislipidemia & $\begin{array}{l}\text { Prednisona, } \\
\text { Azatioprina, } \\
\text { Doxiciclina, }\end{array}$ & $\begin{array}{c}\text { Atividade da } \\
\text { doença }\end{array}$ \\
\hline Paraná & 55 & Afrodescendente & $\begin{array}{l}\text { Diabetes melitus, } \\
\text { Hipertensão } \\
\text { Arterial sistêmica, } \\
\text { Hipotireoidismo, } \\
\text { Doença do refluxo } \\
\text { gastroesofágico, } \\
\text { Osteoartrose, } \\
\text { Transtorno afetivo } \\
\text { bipolar }\end{array}$ & Prednisona & $\begin{array}{l}\text { Remissão } \\
\text { clínica com } \\
\text { tratamento }\end{array}$ \\
\hline São Paulo & 50 & Caucasiano & Osteopenia & Prednisona & Atividade \\
\hline São Paulo & 70 & Caucasiano & $\begin{array}{l}\text { Diabetes melitus, } \\
\text { Hipertensão } \\
\text { Arterial sistêmica }\end{array}$ & $\begin{array}{l}\text { Prednisona, } \\
\text { Azatioprina }\end{array}$ & $\begin{array}{l}\text { Remissão } \\
\text { clinica com } \\
\text { tratamento }\end{array}$ \\
\hline Ceará & 57 & Caucasiano & $\begin{array}{l}\text { Osteoporose com } \\
\text { fratura patológica }\end{array}$ & $\begin{array}{l}\text { Prednisona, } \\
\text { Azatioprina }\end{array}$ & $\begin{array}{l}\text { Remissão } \\
\text { clínica sem } \\
\text { tratamento } \\
\text { (suspensão } \\
\text { tratamento) }\end{array}$ \\
\hline São Paulo & 33 & Caucasiano & $\begin{array}{l}\text { Osteoporose com } \\
\text { fratura patológica }\end{array}$ & $\begin{array}{l}\text { Prednisona, } \\
\text { Azatioprina, } \\
\text { Micofenolato de } \\
\text { Mofetila }\end{array}$ & $\begin{array}{l}\text { Remissão } \\
\text { clinica sem } \\
\text { tratamento } \\
\text { (suspensão } \\
\text { tratamento) }\end{array}$ \\
\hline Itália & 78 & Caucasiano & $\begin{array}{l}\text { Adenocarcinoma } \\
\text { de colón, } \\
\text { Osteopenia, } \\
\text { Fibrilação atrial, } \\
\text { Miocardiopatia } \\
\text { isquêmica, } \\
\text { Insuficiência } \\
\text { cardiaca } \\
\text { congestiva, } \\
\text { Insuficiência renal } \\
\text { crônica, } \\
\text { Aneurisma de } \\
\text { aorta }\end{array}$ & Prednisona & Atividade \\
\hline São Paulo & 54 & Oriental & $\begin{array}{l}\text { Hipertensão } \\
\text { Arterial sistêmica, } \\
\text { Osteopenia }\end{array}$ & $\begin{array}{l}\text { Prednisona, } \\
\text { Micofenolato } \\
\text { mofetila }\end{array}$ & Atividade \\
\hline
\end{tabular}

Legendas: Dx: diagnóstico. 


\subsubsection{Variáveis demográficas e clínicas: Grupo 2}

O paciente do segundo grupo era caucasiano, procedente do sudeste do país (Minas Gerais) e apresentava história prévia de pênfigo folíaceo diagnosticado aos 25 anos de idade e acompanhado em outro serviço. Em sua primeira consulta em nosso ambulatório, 7 anos após diagnóstico de pênfigo folíaceo e em remissão clínica desta dermatose, o paciente apresentava quadro clínico sugestivo de epidermólise bolhosa adquirida com ulcerações na mucosa oral, bolhas cutâneas tensas predominantemente em áreas de trauma, cicatrização com atrofia e formação de mília e lesões esofágicas à endoscopia digestiva alta. Seu tratamento foi baseado no uso de prednisona; porém o paciente apresentava má-aderência as medicações. No curso da doença, ele apresentou estenose esofágica como sequela das lesões bolhosas esofágicas. Suas comorbidades clínicas incluíam asma e quadro reumatológico de poliartrite (diagnosticado 1 ano após ocorrência de EBA) em acompanhamento com a Reumatologia e sem diagnóstico etiológico definido (possível artrite soronegativa). Investigação para lupus eritematoso sistêmica foi realizada com resultados negativos (FAN negativo, URINA tipo I normal, sem anemia ou leucopenia ao hemograma). 


\subsection{Variáveis laboratoriais}

\subsubsection{Variáveis laboratoriais: Grupo 1}

Dados sumarizados na tabela 3 e 4 e Figuras 10-14.

\section{Exame histopatológico}

No grupo 1, em cinco dos oito pacientes a conversão PV-PF foi confirmada por histopatologia, ou seja, os pacientes apresentaram modificação de clivagem suprabasal para acantólise subcórnea (pacientes 3 a 7).

Dois pacientes apresentavam clivagem na camada epidérmica média no momento da suspeita de epitope spreading (pacientes 2 e 1. Figura 10) e um manteve a clivagem suprabasal à histopatologia, a despeito de aspecto clínico de PF (paciente 8. Figura 11). Dois pacientes apresentaram espongiose eosinofilica durante a transição (pacientes 5 e 6). Um dos pacientes (paciente 3. Figuras 12, 13 e 14), após conversão para clivagem subcórnea apresentou retorno a clivagem suprabasal em exames subsequentes.

\section{Imunofluorescência}

Estudos de imunofluorescência direta (IFD) demonstraram deposição intraepitelial de C3 e lgG em todos os pacientes antes e após a conversão clínica; com deposição preferencial de C3 nas camadas inferiores da epiderme em quatro pacientes.

$\mathrm{Na}$ imunofluorescência indireta (IFI) os títulos de anticorpos variaram de $1 / 160$ a $1 / 5120$ e foram positivos durante o epitope spreading. 


\section{ELISA}

Os valores do ELISA para desmogleína 1 variaram de 22 a 319 e para desmogleína 3 de 0,4 a 224. As relações de desmogleína 1/desmogleína 3 corresponderam as mudanças clínicas de PV a PF (aumento do índice no momento da suspeita do ES). Um dos pacientes (paciente 3) apresentou diminuição do valor da relação Dsg1/Dsg3 após aumento inicial (no momento do ES houve aumento da relação e posteriormente sua diminuição), tal modificação acompanhou o retorno de seu exame histopatológico de clivagem subcórnea para suprabasal (PV-PF-PV).

Tabela 3. Sumário dos achados laboratoriais nos pacientes do grupo 1 (PV a PF)

\begin{tabular}{|c|c|c|c|c|c|c|c|}
\hline № & ES (anos) & HP inicial & HP final & IFD inicial & IFD final & IIF inicial & IIF final \\
\hline 1 & 2 & SB & CME & C3-ICIE & C3-ICIE & $1: 5120$ & $1: 320$ \\
\hline 2 & 4 & SB & CME & C3- ICIE baixa & C3, IgG-ICIE & $1: 160$ & $1: 320$ \\
\hline 3 & 4,5 & SB & SC e depois SB & $\begin{array}{l}\text { C3- ICIE baixa } \\
\text { IgG-ICIE }\end{array}$ & $\begin{array}{l}\text { C3- ICIE baixa } \\
\text { IgG-ICIE }\end{array}$ & $1: 640$ & $1: 2560$ \\
\hline 4 & 7 & SB & SC & C3, IgG-ICIE & C3, IgG-ICIE & $1: 320$ & $1: 2560$ \\
\hline 5 & 3 & SB & SC & $\begin{array}{l}\text { C3- ICIE baixa } \\
\text { IgG-ICIE }\end{array}$ & C3, IgG-ICIE & $1: 640$ & $1: 160$ \\
\hline 6 & 3 & SB & SC & C3, IgG-ICIE & C3, IgG-ICIE & $1: 160$ & $1: 640$ \\
\hline 7 & 6 & SB & SC & $\begin{array}{l}\text { C3-ICIE baixa } \\
\text { IgG-ICIE }\end{array}$ & $\operatorname{IgG}-\mathrm{ICIE}$ & $1: 160$ & $1: 160$ \\
\hline 8 & 2 & SB & SB & IgG, C3-ICIE & $\operatorname{IgG}-\mathrm{ICIE}$ & $1: 1280$ & $1: 160$ \\
\hline
\end{tabular}

Legendas: ES: epitope spreading; HP: histopatologia; IFD: imunofluorescência direta; IFI: imunofluorescência indireta; SB: clivagem suprabasal; SC: clivagem subcórnea; CME: clivagem na camada epidérmica média; ICIE: depósitos intercelulares intraepidérmicos. Escala de cinza. Cinza claro: pacientes com clivagem nas camadas epidérmicas médias após suspeita clínica de ES. Cinza médio: pacientes com transição de clivagem suprabasal para subcórnea. Cinza escuro: Persistência de clivagem suprabasal, a despeito de aspecto clínico de Pênfigo folíaceo. 
Tabela 4. Sumário dos valores de ELISA para Desmogléinas 1 e 3 recombinantes nos pacientes do grupo 1 antes e após a suspeita de fenômeno de ES (PV a PF):

\begin{tabular}{|c|c|c|}
\hline PACIENTE & $\begin{array}{l}\text { Desmogléinas antes } \\
\text { suspeita de ES }\end{array}$ & $\begin{array}{l}\text { Desmogléina após } \\
\text { suspeita de ES }\end{array}$ \\
\hline \multirow[t]{2}{*}{1} & Dsg 1: 261 & Dsg 1: 319 \\
\hline & Dsg 3: 179 & Dsg 3: 5 \\
\hline \multirow[t]{2}{*}{2} & Dsg 1: 253 & Dsg 1: 207 \\
\hline & Dsg 3: 207 & Dsg 3: 37 \\
\hline \multirow[t]{2}{*}{3} & Dsg 1: 120 & Dsg 1: 253 \\
\hline & Dsg 3: 224 & Dsg 3: 170 \\
\hline \multirow[t]{2}{*}{4} & Dsg 1: 76 & Dsg 1: 44 \\
\hline & Dsg 3: 188 & Dsg 3: 0.4 \\
\hline \multirow[t]{2}{*}{5} & Dsg 1: 74 & Dsg 1: 27 \\
\hline & Dsg 3: 100 & Dsg 3: 13 \\
\hline \multirow[t]{2}{*}{6} & Dsg 1: NR & Dsg 1: 70 \\
\hline & Dsg 3: NR & Dsg 3: 0.6 \\
\hline \multirow[t]{2}{*}{7} & Dsg 1: 22 & Dsg 1: 186 \\
\hline & Dsg 3: 177 & Dsg 3: 3 \\
\hline \multirow[t]{2}{*}{8} & Dsg 1: 123 & Dsg 1: 190 \\
\hline & Dsg 3: 217 & Dsg 3: 84 \\
\hline
\end{tabular}

Legendas: ES: epitope spreading; Dsg 1: desmogléina 1 recombinante. Dsg 3: Desmogleína 3 recombinante. Cut-off $=20$. 


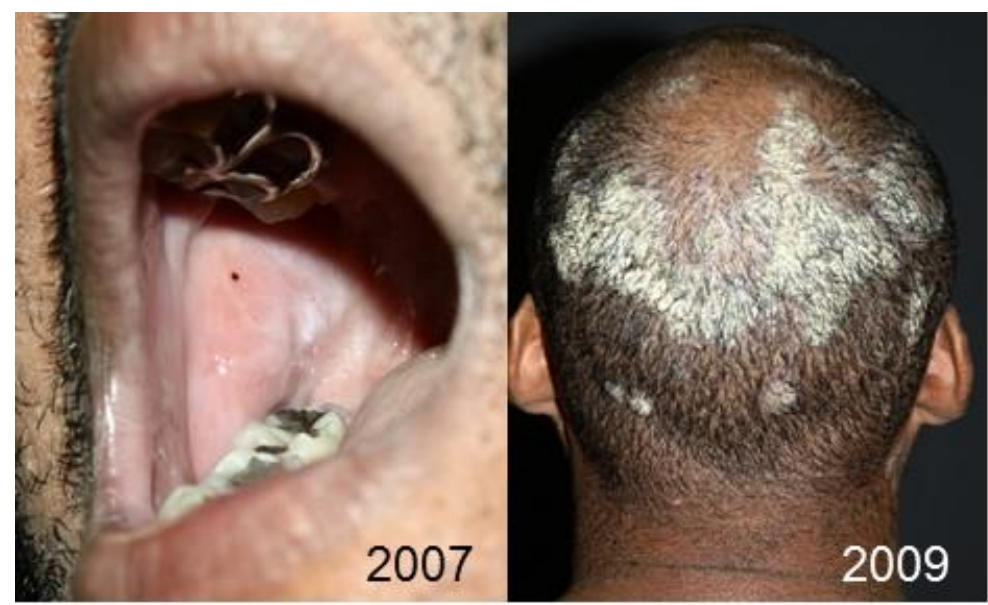

Figura 10. Paciente 1: Em 2007, desenvolvimento de lesões cutâneo mucosas com diagnóstico de PV: clivagem suprabasal à histopatologia e ELISA positivo para Dsg1 e 3 (Dsg1 = 261 Dsg3 = 179 Dsg1/Dsg3=1,45). Em 2009, primeira suspeita de ES para PF, lesões clínicas crostosas couro cabeludo e tronco, ausência de lesões mucosas. Histopatologia com clivagem na camada epidérmica média e ELISA negativo para Dsg3 no momento da suspeita de ES (Dsg1 = 319 Dsg3 = 5 Dsg1/Dsg3=63,8)

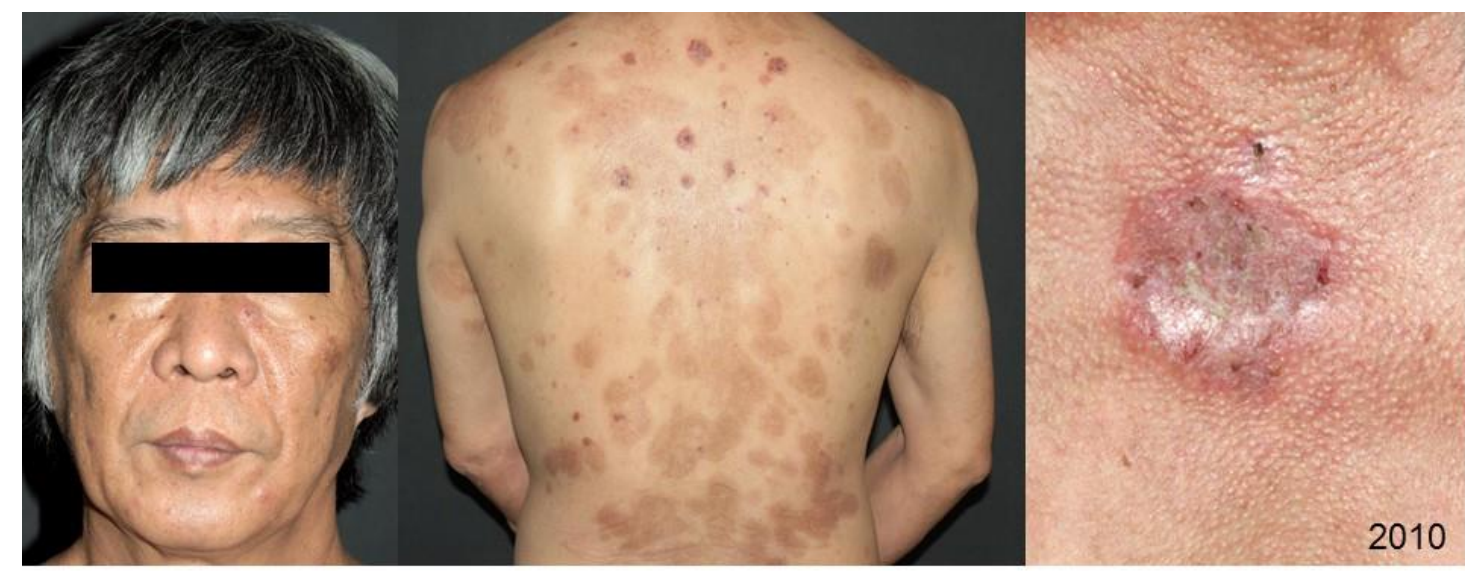

Figura 11. Paciente 8. Lesões cutâneo mucosas no diagnóstico inicial de PV em 2008, apresentou remissão clínica 2 anos após tratamento com prednisona e micofenolato mofetila. Dois meses após interrupção desde tratamento; houve recidiva com quadro clínico sugestivo de PF (fotos acima). À histopatologia houve persistência de clivagem suprabasal e persistência de positividade à Dsg3, no entanto a relação Dsg1/Dsg3 demonstrou aumento no momento da suspeita de ES e em controle posterior (de 0,56 em 2008, a 2,09 em 2010 e 2,26 em 2011) 


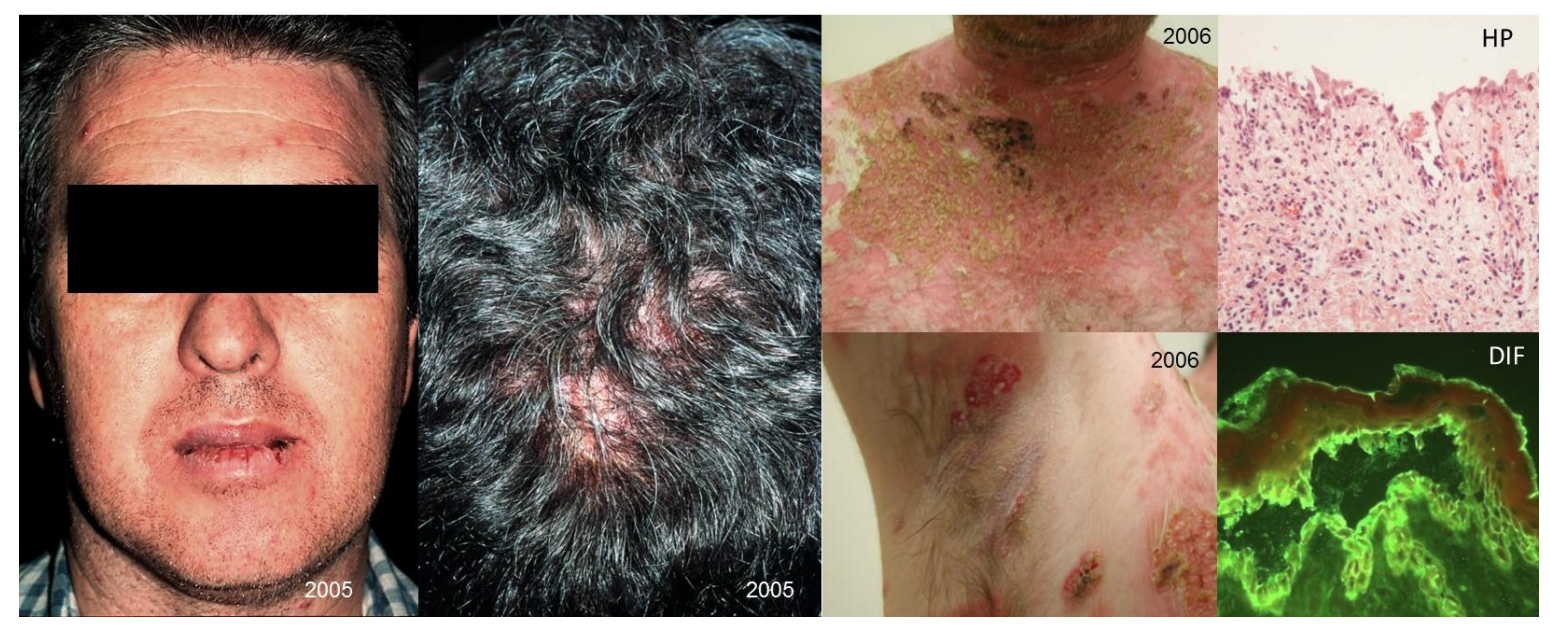

Figura 12. Paciente 3. Lesões cutâneo mucosas no diagnóstico inicial de PV (outubro de 2003), apresentou exacerbação da doença em 2006. À histopatologia (HP) detectou-se clivagem suprabasal com fluorescência intercelular intraepidérmica de IgG à IFD. Neste momento os valores de ELISA para Dsg1 foram de 120 e Dsg3 224 (relação de 0,53)

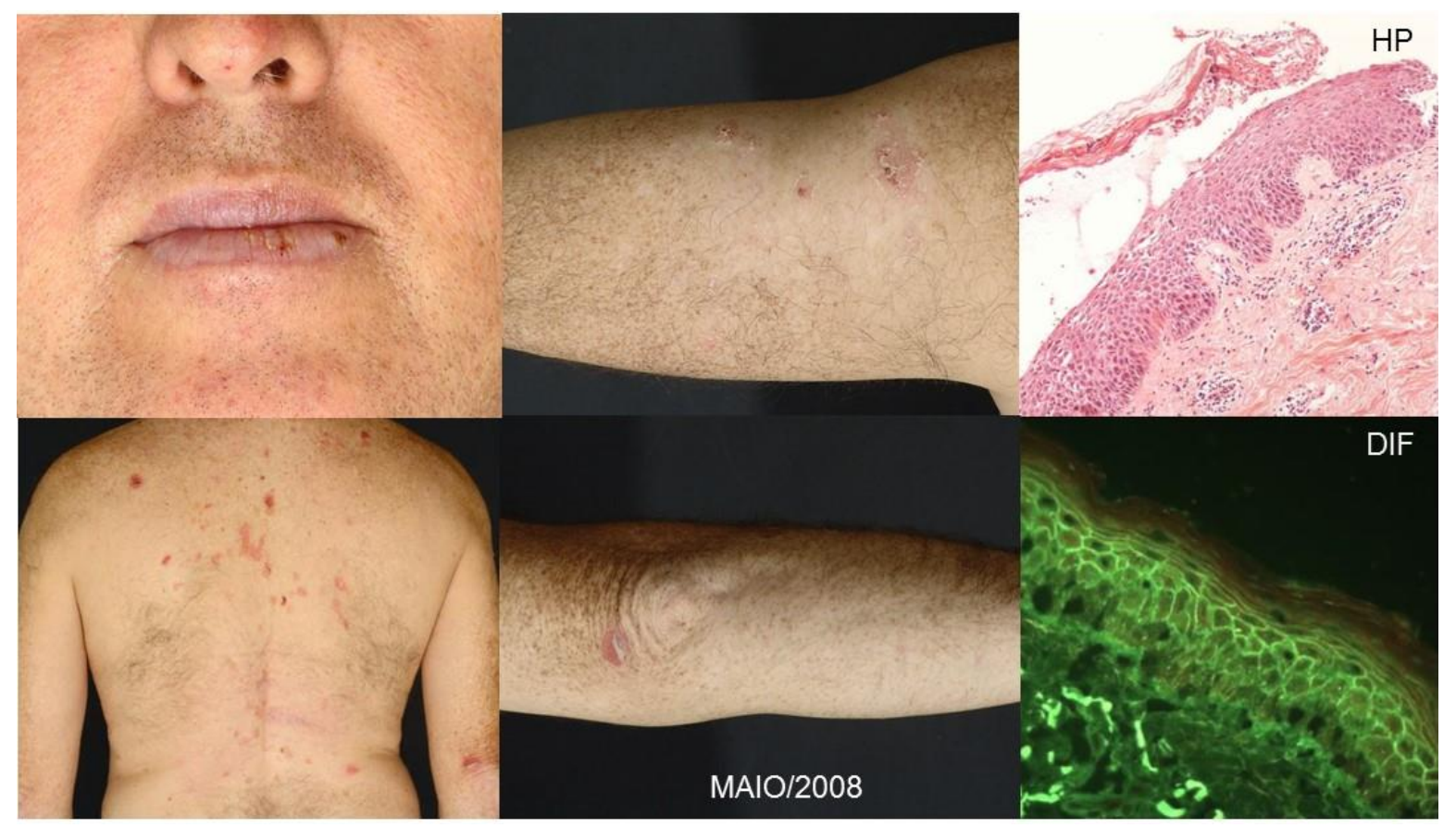

Figura 13. Paciente 3. Em 2008, suspeita de ES a PF devido modificação do quadro clínico (lesões crostosas no tronco e membros, persistiam lesões da mucosa labial porém sem lesões na mucosa oral). À histopatologia (HP) detectou-se clivagem subcórnea com fluorescência intercelular intraepidérmica de IgG à IFD. Neste momento os valores de ELISA para Dsg1 foram de $174 \mathrm{e}$ Dsg3 95 (relação de 1,8) 


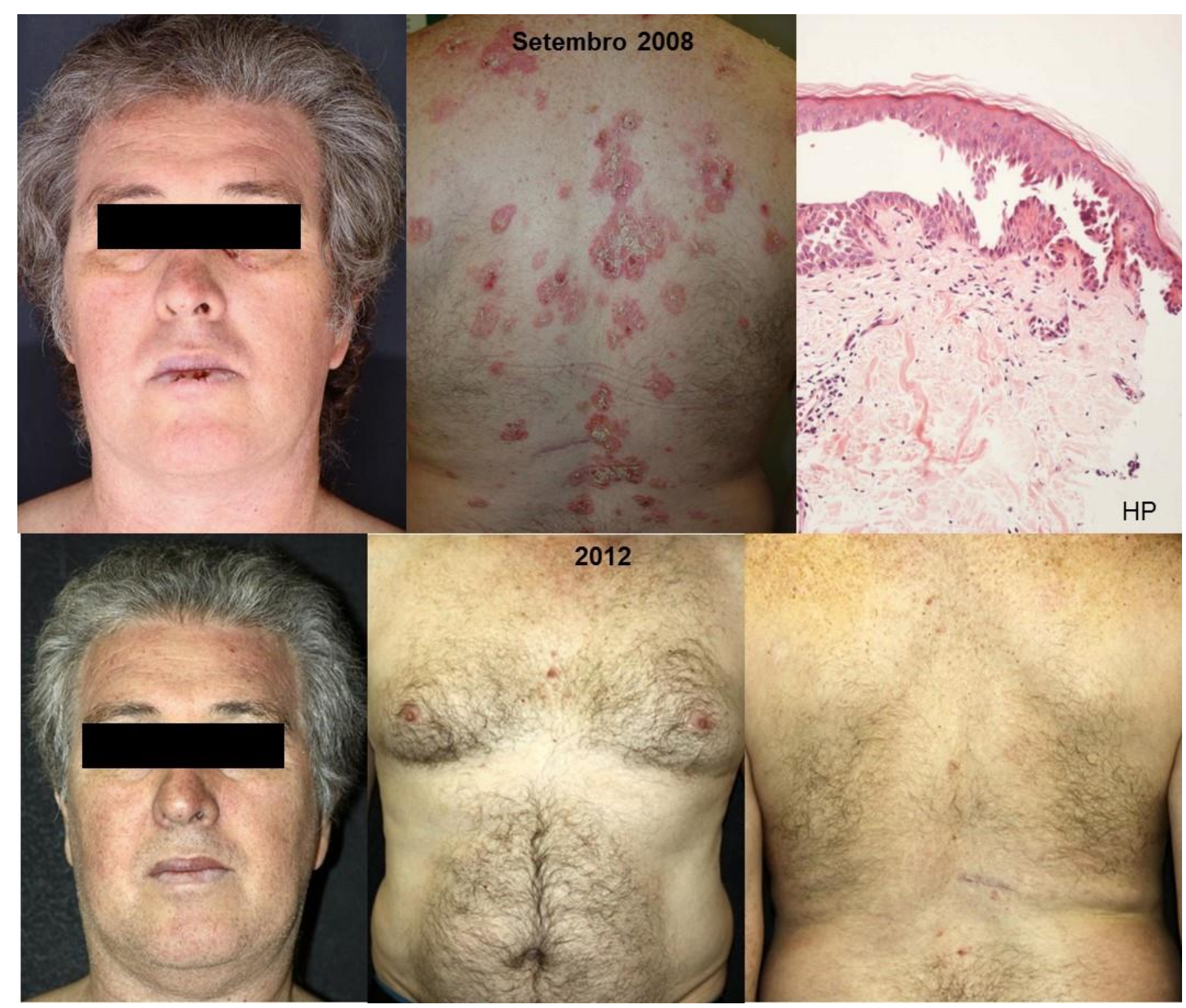

Figura 14. Paciente 3. Retorno de aspecto de PV em setembro de 2008: lesões mucosas e clivagem suprabasal à histopatologia. Em 2012, aspecto clínico de PF, com ausência de lesões mucosas e presença de lesões crostosas esparsas no tronco; porém os valores de ELISA para Dsg1 foram de 253 e Dsg3 170 (relação de 1,48, tendência à diminuição do índice quando comparado ao valor no momento do ES) 


\subsubsection{Variáveis laboratoriais: Grupo 2}

\section{Exame histopatológico}

A histopatologia, realizada no momento da primeira consulta em nosso serviço, revelou clivagem subepidérmica com infiltrado neutrofílico.

\section{Imunofluorescência}

A imunofluorescência direta (IFD) detectou depósitos lineares de IgM, $\lg A$, IgG e C3 na zona da membrana basal e depósitos intercelulares intraepidérmicos discretos focais de C3. A imunofluorescência indireta (IFI) demonstrou depósitos de lgG intraepidérmicos (intercelular, título de 1:640), e na zona da membrana basal (linear, 1:20). IFI com técnica de salt split skin revelou depósitos de lgG do lado dérmico da clivagem.

\section{Exames imunosorológicos}

Immunoblotting revelou IgG anti colágeno VII e ELISA foi positivo para Dsg1 (valor 105; cut-off=20).

Os achados laboratoriais referentes ao paciente do Grupo 2, são sumarizados na Figura 15, a seguir. 


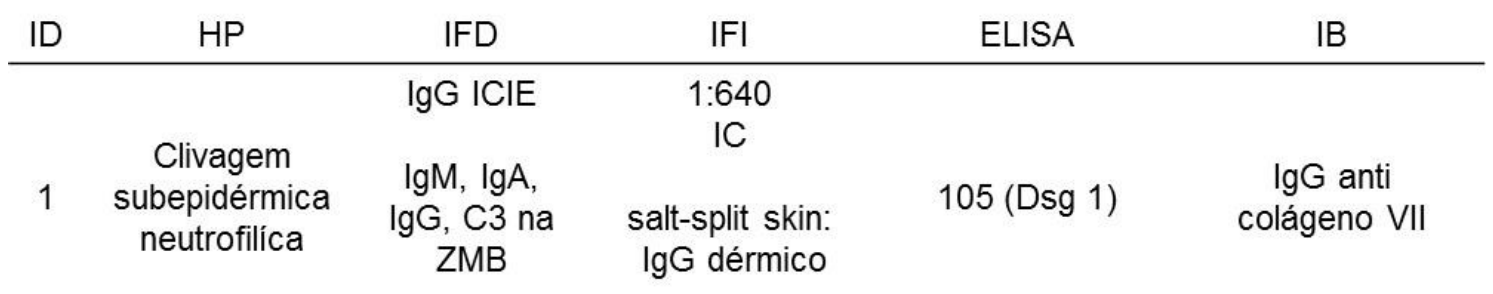
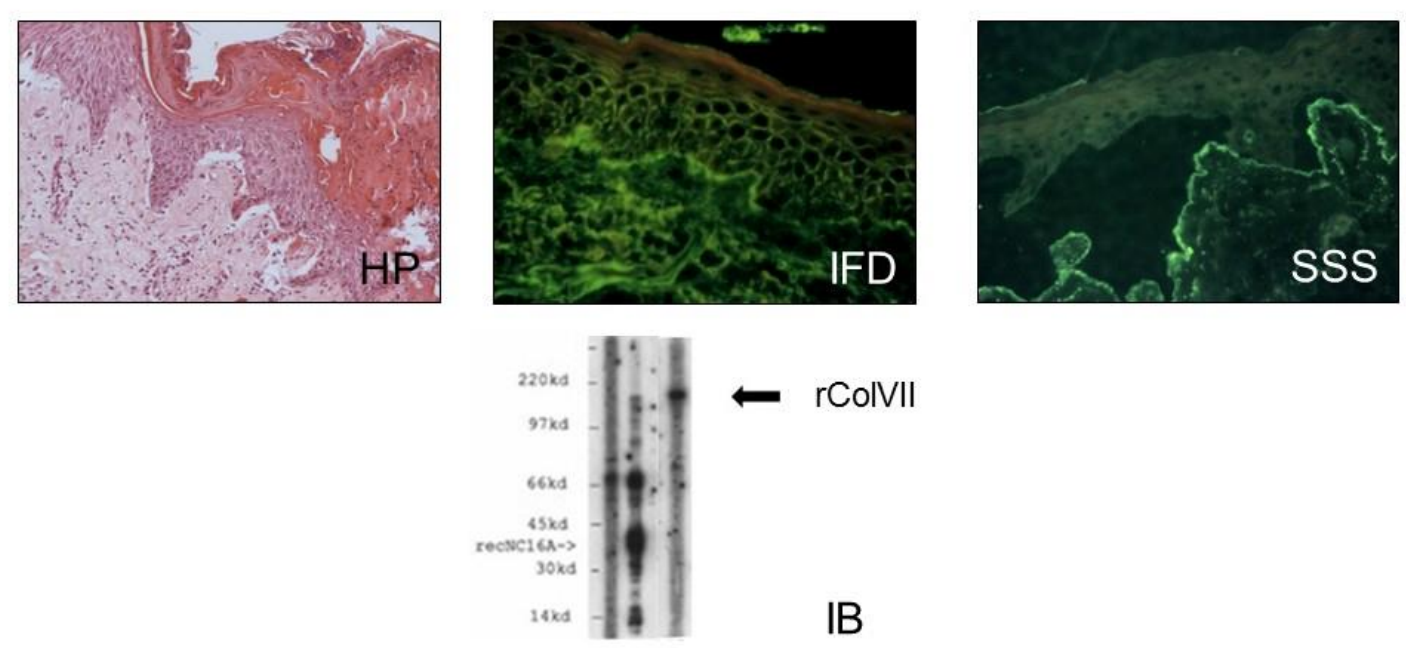

Figura 15. Achados laboratoriais no paciente do grupo 2. Legendas: ICIE: depósitos intercelulares intraepidérmicos; IC: depósitos intercelulares; ZMB: zona da membrana basal; HP: histopatologia, IFD: imunofluorescência direta, SSS salt split skin, IB: immunoblotting 
6 DISCUSSÃO 
Nossos achados demonstram que o epitope spreading em pacientes portadores de dermatoses bolhosas ocorreu predominantemente nos portadores de dermatoses bolhosas intraepidérmicas (pênfigos), como a conversão de pênfigo vulgar a pênfigo folíaceo e com tempo para ES variando de 2 a 7 anos. Tais dados são compatíveis com os relatos da literatura ${ }^{(27-40)}$. Esta predominância de fenômenos de epitope spreading no subgrupo dos pênfigos, poderia correlacionar-se com a homologia estrutural das Dsg1 e 3 e à sua proximidade na epiderme; no entanto a variabilidade no tempo de conversão sugere que fatores genéticos e ambientais também possa participar deste processo.

Com relação ao quadro clínico e evolução da doença após o ES, nos oito pacientes do grupo 1, quatro apresentaram remissão clínica ao término do estudo e quatro persistiam em atividade. Após o ES, o quadro clínico destes pacientes caracterizou-se por doença mais leve sugerindo um melhor prognóstico após a conversão. Com relação aos achados laboratoriais no grupo 1, quatro dos cinco pacientes cuja conversão foi confirmada à histopatologia apresentavam valores de ELISA anti Dsg3 negativos (menores do que 20; cut-off de positividade). Entre os 2 pacientes com clivagem média à histopatologia, um apresentou negativação do ELISA à Dsg3 no momento da conversão clínica. Os demais pacientes mantiveram positividade ao exame, no entanto a relação Dsg1/Dsg3 correlacionou-se com a conversão em todos os pacientes (aumento no índice) no momento da suspeita do ES. 
Komai et $\mathrm{al}^{(36)}$ analisaram o soro de 5 pacientes que apresentaram conversão de PV para PF, todos apresentavam valores negativos de Dsg3 no momento da transição, exceto por um que apesar de características clínicas de PF mantinha positividade à Dsg1 e 3. Harman et al $^{(32)}$ descreveu caso de paciente com sinais de transição de PV a PF que foi acompanhado sorologicamente com dosagens seriadas de ELISA por um período de 9 anos, no momento de diagnóstico de PV ambas as Dsg (1 e 3) foram positivas ao ELISA, no momento da suspeita de ES havia manutenção da positividade à Dsg3, a qual foi declinando progressivamente até a negativação de seus valores.

Os exames de ELISA refletem devido à natureza policlonal do soro dos pacientes, tanto anticorpos patogênicos como não patogênicos ${ }^{(5)}$. O que poderia explicar a positividade à Dsg3 apesar de fenótipo de PF. Além disso, considerando que os fenômenos de epitope spreading são um processo evolutivo, amostras seriadas são geralmente necessárias para detecção da transição laboratorial durante os fenômenos de ES. Em nosso estudo amostras sequencias e a intervalos mais frequentes poderiam ter sido úteis para 0 mapeamento da conversão PV-PF.

Com relação ao paciente 3 (Figuras 8, 9 e 10), que apresentou achados clínicos e laboratoriais sugestivos de conversão de PV a PF com posterior retorno a PV, um relato semelhante foi encontrado na literatura. Chorzelski et $\mathrm{al}^{(29)}$ descreveram paciente que apresentava quadro clínico inicial de pênfigo vulgar com lesões cutâneo mucosas típicas. Após 1 ano houve desenvolvimento de bolhas flácidas com padrão histológico típico de pênfigo folíaceo focalmente em associação a áreas de clivagem suprabasal. Os níveis de ELISA a Desmogleína 3 apresentaram negativação durante o diagnóstico de PF com 
recrudescência posterior. Em nosso paciente, um aumento na relação Dsg1/Dsg3 ao ELISA (sugerindo diminuição da positividade à Dsg3) foi detectado no momento da conversão clínica e histopatológica (clivagem subcórnea) para PF; porém retorno ao padrão histopatológico de PV (clivagem suprabasal) ocorreu 4 meses depois. Em 2012, ao término deste levantamento, o paciente apresentava quadro clínico típico de PF, no entanto mantinha positividade à Dsg3 (com diminuição no índice Dsg1/Dsg3). Um tempo de seguimento maior será necessário neste paciente a fim de verificar a progressão e padrão laboratorial de sua doença. Seus achados laboratoriais, apesar de controversos, reforçam os fenômenos de epitope spreading como um processo evolutivo e dinâmico.

Com relação ao paciente do grupo 2, a transição entre dermatoses intraepidérmicas a subepidérmicas é mais rara, e tem sido relatada principalmente em associação com penfigóide bolhoso ${ }^{(48-51,53)}$. Até o momento, este é o primeiro relato de uma transição entre PF e EBA, com coexistência de achados imunológicos a ambas as doenças.

A coexistência de autoanticorpos a diferentes antígenos em dermatoses bolhosas autoimunes foi descrita por alguns autores, incluindo Zakka et al ${ }^{(52)}$; os quais analisaram soro de 15 pacientes com PV que apresentaram aproximadamente 6,6 anos após o diagnóstico inicial autoanticorpos a antígenos de PB. Neste estudo, as moléculas de MHCII dos pacientes foram analisadas e os autores demonstraram que tais moléculas reconheciam epítopos relevantes para ambas as doenças, sugerindo que dois autoanticorpos foram produzidos simultaneamente devido a fenômenos de epitope spreading. Tais pacientes apresentavam doença refratária às terapias tradicionais e caracterizada por múltiplas remissões e recidivas. 
Nosso paciente, além de coexistência de autoanticorpos dirigidos a antígenos de PF e EBA, apresentava também quadro reumatológico de artrite soronegativa sugerindo uma tendência ao desenvolvimento de fenômenos de ES, com resposta desfavorável de seu sistema imune e produção de autoanticorpos a diferentes antígenos simultaneamente. Mais estudos serão necessários para elucidar os fatores envolvidos no desencadeamento deste processo. 


\section{CONCLUSÕES}


1. Este é o primeiro estudo de longo seguimento, com grande número de pacientes, que analisa o epitope spreading intermolecular nos pênfigos. A ocorrência de modificação clínica sugestiva de fenômeno de ES em 9 de $351(2,6 \%)$ pacientes analisados sugere que este fenômeno seja mais frequente do que os 31 casos relatados na literatura até o momento.

2. O predomínio da conversão PV para PF sugere que a homologia estrutural e proximidade de localização dos antígenos das Desmogleínas 1 e 3 tenham papel importante na ocorrência do fenômeno de ES.

3. Os pacientes que apresentaram conversão de PV para PF, evoluíram com quadro clínico mais leve, sendo que 4 de 8 (50\%) pacientes estavam em remissão clínica ao término do estudo, sugerindo melhor prognóstico após a conversão.

4. Devemos suspeitar de fenômenos de epitope spreading em pacientes portadores de dermatoses bolhosas autoimunes que apresentem modificação no aspecto clínico durante a evolução da doença primária.

5. Nosso estudo foi o primeiro a relatar a conversão entre pênfigo foliáceo e epidermólise bolhosa adquirida.

O impacto dos fenômenos de epitope spreading no curso e progressão das doenças bolhosas autoimunes ainda necessita ser elucidado, sua compreensão poderá influenciar o desenvolvimento de terapias direcionadas (especificamente a linfócitos T ou B) e a prevenção das doenças autoimunes. 


\section{ANEXOS}




\section{ANEXO 1: TERMO DE CONSENTIMENTO LIVRE E ESCLARECIDO}

\section{hOSPITAL DAS CLÍNICAS DA FACULdADE DE MEDICINA DA UNIVERSIDADE DE SÃO PAULO-HCFMUSP}

\section{TERMO DE CONSENTIMENTO LIVRE E ESCLARECIDO}

\section{DADOS DE IDENTIFICAÇÃO DO SUJEITO DA PESQUISA OU RESPONSÁVEL LEGAL}

\section{NOME:}

DOCUMENTO DE IDENTIDADE № : SEXO :.$M \square F \square$

DATA NASCIMENTO: /..................

ENDEREÇO № APTO:

BAIRRO: CIDADE.

CEP:. .TELEFONE:DDD( .).

2.RESPONSÁVEL LEGAL

NATUREZA (grau de parentesco, tutor, curador etc.) DOCUMENTO DE IDENTIDADE: SEXO: $M \square F \square$ DATA NASCIMENTO. № APTO: ENDEREÇO:

BAIRRO: CIDADE: CEP:. TELEFONE:DDD

\section{DADOS SOBRE A PESQUISA}

1. TÍTULO DO PROTOCOLO DE PESQUISA :

Fenômeno de epitope spreading: caracterização clínico-imunológica em pacientes portadores de dermatoses bolhosas autoimunes

PESQUISADOR : Dra Valéria Aoki CARGO/FUNÇÃO: Departamento de Dermatologia do Hospital das Clínicas da Faculdade de MEdicina da Universidade de São Paulo.

INSCRIÇÃO CONSELHO REGIONAL № CRM 60080- SP

UNIDADE DO HCFMUSP: Departamento de Dermatologia

3. AVALIAÇÃO DO RISCO DA PESQUISA:

$\begin{array}{lll}\text { RISCO MÍNIMO } & \square & \text { RISCO MÉDIO } \\ \text { RISCO BAIXO } & X & \text { RISCO MAIOR }\end{array}$




\section{HOSPITAL DAS CLÍNICAS DA FACULDADE DE MEDICINA DA UNIVERSIDADE DE SÃO PAULO-HCFMUSP}

Você está sendo convidado a participar de uma pesquisa clínica, que será realizada em pacientes que tenham uma doença bolhosa autoimune da pele, para estudar sua resposta imunológica. Temos visto que alguns pacientes evoluem de um tipo de doença, por exemplo pênfigo foliáceo, para outra, por exemplo pênfigo vulgar e gostaríamos de entender melhor o porquê desta mudança. Participando, você estará ajudando na tentativa de descobrir a causa deste processo.

Antes de tomar uma decisão é importante que você compreenda porque esta pesquisa clínica está sendo realizada e o que ela envolverá. Por favor, leia com atenção este documento e faça as perguntas que desejar.

O objetivo deste estudo é verificar a resposta do sistema imune em pacientes que tiveram mudança no seu tipo de doença bolhosa, através de exames que já são normalmente realizados para os pacientes seguidos no ambulatório: biópsia de pele e exames de sangue.

Se você decidir participar e assinar este Termo, você responderá a um questionário sobre sua doença e será submetido a um exame dermatológico. Após, serão realizadas duas biópsias de pele com anestesia local, no ambulatório, em data agendada, no qual, retira-se um pequeno pedaço da pele, fechando-se com um ponto logo em seguida. O ponto será retirado entre 5 a 14 dias dependendo do local da biópsia. A biópsia da pele pode causar leve dor local durante a realização e nas horas seguintes, formação de arroxeado temporário no local, infecção local, e formação de pequena cicatriz.

A coleta de sangue é feita por punção da veia do antebraço, em data préagendada e o material será enviado para exames imunológicos (Imunofluorescência indireta e ELISA) para identificar os tipos de anticorpos presentes em cada paciente. A coleta de sangue pode causar leve dor ou desconforto durante o procedimento e, logo após, arroxeado local.

Caso estes desconfortos the ocorram de maneira intensa, você poderá procurar o Departamento de Dermatologia do Hospital das Clínicas da FMUSP , para tratamento, sem custo algum.

Em qualquer etapa do estudo, você terá acesso aos profissionais responsáveis pela pesquisa para esclarecimento de eventuais dúvidas. O principal investigador é que pode ser encontrado no Ambulatório de Dermatologia do Hospital das Clínicas da Faculdade de Medicina da Universidade de São Paulo. Rua Dr. Eneas de Carvalho Aguiar 1555 andar. Cerqueira Cesar São Paulo SP CEP 05403-000 Telefone(s): 30696050.

Se você tiver alguma consideração ou dúvida sobre a ética da pesquisa, entre em contato com o Comitê de Ética em Pesquisa (CEP) - Rua Ovídio Pires de Campos, 225 - 5 andar - tel: 3069-6442 ramais 16, 17, 18 ou 20, FAX: 3069-6442 ramal 26 E-mail: cappesq@hcnet.usp.br

Você poderá retirar seu consentimento a qualquer momento e você deixará de participar do estudo, sem que haja qualquer prejuízo quanto à continuidade de seu tratamento pelo mesmo hospital, devendo apenas informar ao médico responsável o motivo que o levou a se retirar do estudo. As informações obtidas serão analisadas em 
conjunto com as dos outros pacientes, não sendo divulgado a identificação de nenhum paciente. Nos comprometemos a mantê-lo atualizado sobre os resultados parciais das pesquisas que forem do nosso conhecimento.

Você não pagara nada para participar do estudo, mas também não receberá nenhuma ajuda financeira. A sua participação estará contribuindo para um melhor conhecimento sobre sua doença. As informações coletadas serão usadas somente para esta pesquisa.

Acredito ter sido suficientemente informado a respeito das informações que li ou que foram lidas para mim, descrevendo o estudo"

Fenômeno de epitope spreading: caracterização clínico-imunológica em pacientes portadores de dermatoses bolhosas autoimunes

Eu discuti com a Dra sobre a minha decisão em participar nesse estudo. Ficaram claros para mim quais são os propósitos do estudo, os procedimentos a serem realizados, seus desconfortos e riscos, as garantias de confidencialidade e de esclarecimentos permanentes. Ficou claro também que minha participação é isenta de despesas e que tenho garantia do acesso a tratamento hospitalar quando necessário. Concordo voluntariamente em participar deste estudo e poderei retirar o meu consentimento a qualquer momento, antes ou durante o mesmo, sem penalidades ou prejuízo ou perda de qualquer benefício que eu possa ter adquirido, ou no meu atendimento neste Serviço.

Assinatura do paciente/representante lega

Data $1 /$

Assinatura da testemunha

Data 11

para casos de pacientes menores de 18 anos, analfabetos, semianalfabetos ou portadores de deficiência auditiva ou visual.

(Somente para o responsável do projeto)

Declaro que obtive de forma apropriada e voluntária o Consentimento Livre e Esclarecido deste paciente ou representante legal para a participação neste estudo. 


\title{
ANEXO II: Aprovação do protocolo de Pesquisa
}

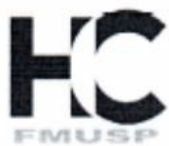

\author{
Hospital das Clínicas da FMUSP \\ Comissão de Ética para Análise de Projetos de Pesquisa \\ CAPPesq
}

$N^{\circ}$ Protocolo: $0568 / 11$

Título: FENÔMENO DE "EPITOPE SPREADING": CARACTERIZAÇÃO CLÍNICOIMUNOLÓGICA EM PACIENTES PORTADORES DE DERMATOSES BOLHOSAS AUTO-IMUNES

Pesquisador Responsável: Valéria Aoki

Pesquisador Executante: Lívia Delgado

Co-autores: Dra. Celina W. Maruta

Finalidade Acadêmica: Pesquisa Clínica

Departamento: DERMATOLOGIA

A Comissão de Ética para Análise de Projetos de Pesquisa CAPPesq da Diretoria Clínica do Hospital das Clínicas da Faculdade de Medicina da Universidade de São Paulo, APROVOU / TOMOU CIÊNCIA na sessão datada de 19/10/2011 o protocolo acima.

A CAPPesq em obediência à Resolução CNS 196/96, solicita ao pesquisador (a) s elaboração de relatório parcial e final.

No caso de relatório parcial é necessário informar o tempo previsto para a conclusão do protocolo e breve resumo dos resultados obtidos.

CAPPesq. 21 de Outubro de 2011

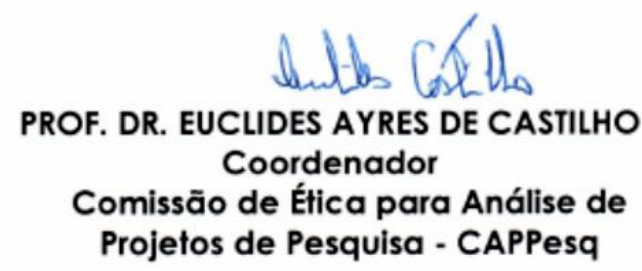

Rua Dr. Ovidio Pires de Campos, 225 - Prédio da Administraçăo - $5^{\circ}$ andar - CEP 05403-010 - Săo Paulo - SP. Fone: $55112661-6442$ ramais 16, 17, 18 e 20 - e-mail: cappesq@hcnet.usp.br 


\section{REFERÊNCIAS}


1. Mutasim DF, Adams BB. Immunofluorescence in dermatology. Journal of the American Academy of Dermatology. 2001;45(6):803-22; quiz 22-4.

2. Kneisel A, Hertl M. Autoimmune bullous skin diseases. Part 2: diagnosis and therapy. Journal der Deutschen Dermatologischen Gesellschaft $=$ Journal of the German Society of Dermatology : JDDG. 2011;9(11):927-47.

3. Mutasim DF. Management of autoimmune bullous diseases: pharmacology and therapeutics. Journal of the American Academy of Dermatology. 2004;51(6):859-77; quiz 78-80.

4. Abasq C, Mouquet H, Gilbert D, Tron F, Grassi V, Musette P, et al. ELISA testing of anti-desmoglein 1 and 3 antibodies in the management of pemphigus. Archives of dermatology. 2009;145(5):529-35.

5. Amagai M, Stanley JR. Desmoglein as a target in skin disease and beyond. The Journal of investigative dermatology. 2012;132(3 Pt 2):776-84.

6. Tchernev G, Orfanos CE. Antigen mimicry, epitope spreading and the pathogenesis of pemphigus. Tissue Antigens. 2006;68(4):280-6.

7. Rook. Textbook of Dermatology. 8th Edition ed: Wiley-Blackwell; 2010.

8. Zillikens D. Acquired skin disease of hemidesmosomes. Journal of dermatological science. 1999;20(2):134-54.

9. Hanakawa $\mathrm{Y}$, Amagai M, Shirakata $\mathrm{Y}$, Yahata $\mathrm{Y}$, Tokumaru S, Yamasaki K, et al. Differential effects of desmoglein 1 and desmoglein 3 on desmosome formation. The Journal of investigative dermatology. 2002;119(6):1231-6.

10. Aoki V, Sousa JX, Jr., Fukumori LM, Perigo AM, Freitas EL, Oliveira ZN. Direct and indirect immunofluorescence. Anais brasileiros de dermatologia. 2010;85(4):490-500. 
11. Liu Z, Diaz LA, Troy JL, Taylor AF, Emery DJ, Fairley JA, et al. A passive transfer model of the organ-specific autoimmune disease, bullous pemphigoid, using antibodies generated against the hemidesmosomal antigen, BP180. The Journal of clinical investigation. 1993;92(5):2480-8.

12. Liu Z, Giudice GJ, Zhou X, Swartz SJ, Troy JL, Fairley JA, et al. A major role for neutrophils in experimental bullous pemphigoid. The Journal of clinical investigation. 1997;100(5):1256-63.

13. Schmidt E, Zillikens D. Modern diagnosis of autoimmune blistering skin diseases. Autoimmunity reviews. 2010;10(2):84-9.

14. Gupta R, Woodley DT, Chen M. Epidermolysis bullosa acquisita. Clinics in dermatology. 2012;30(1):60-9.

15. Cornaby C, Gibbons L, Mayhew V, Sloan CS, Welling A, Poole BD. B cell epitope spreading: Mechanisms and contribution to autoimmune diseases. Immunol Lett. 2015;163(1):56-68.

16. Chan LS, Vanderlugt CJ, Hashimoto T, Nishikawa T, Zone JJ, Black MM, et al. Epitope spreading: lessons from autoimmune skin diseases. The Journal of investigative dermatology. 1998;110(2):103-9.

17. Bernard CC, Johns TG, Slavin A, Ichikawa M, Ewing C, Liu J, et al. Myelin oligodendrocyte glycoprotein: a novel candidate autoantigen in multiple sclerosis. Journal of molecular medicine. 1997;75(2):77-88.

18. Steinman L. Multiple sclerosis. Presenting an odd autoantigen. Nature. 1995;375(6534):739-40.

19. Singh RR. Prevention and control of reciprocal T-B cell diversification: implications for lupus-like autoimmunity. Molecular immunology. 2004;40(14-15):1137-45.

20. Vanderlugt CJ, Miller SD. Epitope spreading. Current opinion in immunology. 1996;8(6):831-6. 
21. aoki v If, yamazaki m.h., santi c.g., maruta c.w. Significado do "epitope spreading" na patogênese dos pênfigos vulgar e folíaceo. An Bras Dermatol. 2008;83(2):5.

22. Cusick MF, Libbey JE, Fujinami RS. Molecular mimicry as a mechanism of autoimmune disease. Clinical reviews in allergy \& immunology. 2012;42(1):102-11.

23. Ohtaki A, Kieber-Emmons T, Murali R. Structure-based peptide mimicry of tumor-associated antigens. Monoclonal antibodies in immunodiagnosis and immunotherapy. 2013;32(1):1-5.

24. Aoki V, Rivitti EA, Diaz LA. Update on fogo selvagem, an endemic form of pemphigus foliaceus. J Dermatol. 2015;42(1):18-26.

25. Li N, Aoki V, Hans-Filho G, Rivitti EA, Diaz LA. The role of intramolecular epitope spreading in the pathogenesis of endemic pemphigus foliaceus (fogo selvagem). J Exp Med. 2003;197(11):1501-10.

26. Salato VK, Hacker-Foegen MK, Lazarova Z, Fairley JA, Lin MS. Role of intramolecular epitope spreading in pemphigus vulgaris. Clinical immunology. 2005;116(1):54-64.

27. Iwatsuki K, Takigawa M, Hashimoto T, Nishikawa T, Yamada M. Can pemphigus vulgaris become pemphigus foliaceus? Journal of the American Academy of Dermatology. 1991;25(5 Pt 1):797-800.

28. Kawana S, Hashimoto T, Nishikawa T, Nishiyama S. Changes in clinical features, histologic findings, and antigen profiles with development of pemphigus foliaceus from pemphigus vulgaris. Archives of dermatology. 1994;130(12):1534-8.

29. Chorzelski TP, Hashimoto T, Jablonska S. Pemphigus vulgaris transforming into pemphigus foliaceus and their coexistence. European journal of dermatology : EJD. 1995;5:386-90. 
30. Chang SN, Kim SC, Lee IJ, Seo SJ, Hong CK, Park WH. Transition from pemphigus vulgaris to pemphigus foliaceus. The British journal of dermatology. 1997;137(2):303-5.

31. Mendiratta V, Sarkar R, Sharma RC, Korann RV. Transition of pemphigus vulgaris to pemphigus foliaceus. Indian journal of dermatology, venereology and leprology. 2000;66(2):85-6.

32. Harman KE, Gratian MJ, Shirlaw PJ, Bhogal BS, Challacombe SJ, Black MM. The transition of pemphigus vulgaris into pemphigus foliaceus: a reflection of changing desmoglein 1 and 3 autoantibody levels in pemphigus vulgaris. The British journal of dermatology. 2002;146(4):684-7.

33. Toth GG, Pas HH, Jonkman MF. Transition of pemphigus vulgaris into pemphigus foliaceus confirmed by antidesmoglein ELISA profile. Int $J$ Dermatol. 2002;41(8):525-7.

34. Tsuji Y, Kawashima T, Yokota K, Tateish Y, Tomita Y, Matsumura T, et al. Clinical and serological transition from pemphigus vulgaris to pemphigus foliaceus demonstrated by desmoglein ELISA system. Archives of dermatology. 2002;138(1):95-6.

35. Ng PP, Thng ST. Three cases of transition from pemphigus vulgaris to pemphigus foliaceus confirmed by desmoglein ELISA. Dermatology. 2005;210(4):319-21.

36. Komai A, Amagai M, Ishii K, Nishikawa T, Chorzelski T, Matsuo I, et al. The clinical transition between pemphigus foliaceus and pemphigus vulgaris correlates well with the changes in autoantibody profile assessed by an enzyme-linked immunosorbent assay. The British journal of dermatology. 2001;144(6):1177-82.

37. Espana A, Koga H, Suarez-Fernandez R, Ohata C, Ishii N, Irarrazaval I, et al. Antibodies to the amino-terminal domain of desmoglein 1 are retained during transition from pemphigus vulgaris to pemphigus foliaceus. European journal of dermatology : EJD. 2014;24(2):174-9. 
38. Ito T, Moriuchi R, Kikuchi K, Shimizu S. Rapid transition from pemphigus vulgaris to pemphigus foliaceus. Journal of the European Academy of Dermatology and Venereology : JEADV. 2014.

39. Hashimoto T, Konohana A, Nishikawa T. Immunoblot assay as an aid to the diagnoses of unclassified cases of pemphigus. Archives of dermatology. $1991 ; 127(6): 843-7$.

40. Kimoto M, Ohyama M, Hata Y, Amagai M, Nishikawa T. A Case of pemphigus foliaceus which occurred after five years of remission from pemphigus vulgaris. Dermatology. 2001;203(2):174-6.

41. Ishii K, Amagai M, Ohata Y, Shimizu H, Hashimoto T, Ohya K, et al. Development of pemphigus vulgaris in a patient with pemphigus foliaceus: antidesmoglein antibody profile shift confirmed by enzyme-linked immunosorbent assay. Journal of the American Academy of Dermatology. 2000;42(5 Pt 2):859-61.

42. Park SG, Chang JY, Cho YH, Kim SC, Lee MG. Transition from pemphigus foliaceus to pemphigus vulgaris: case report with literature review. Yonsei Med J. 2006;47(2):278-81.

43. Pigozzi B, Peserico A, Schiesari L, Alaibac M. Pemphigus foliaceus evolving into pemphigus vulgaris: a probable example of 'intermolecular epitope spreading' confirmed by enzyme-linked immunosorbent assay study. Journal of the European Academy of Dermatology and Venereology : JEADV. 2008;22(2):242-4.

44. Awazawa R, Yamamoto Y, Gushi M, Taira K, Yagi N, Asato Y, et al. Case of pemphigus foliaceus that shifted into pemphigus vulgaris after adrenal tumor resection. J Dermatol. 2007;34(8):549-55.

45. Peterson JD, Chang AJ, Chan LS. Clinical evidence of an intermolecular epitope spreading in a patient with pemphigus foliaceus converting into bullous pemphigoid. Archives of dermatology. 2007;143(2):272-4. 
46. Maeda JY, Moura AK, Maruta CW, Santi CG, Prisayanh PS, Aoki V. Changes in the autoimmune blistering response: a clinical and immunopathological shift from pemphigus foliaceus to bullous pemphigoid. Clinical and experimental dermatology. 2006;31(5):653-5.

47. Recke A, Rose C, Schmidt E, Brocker EB, Zillikens D, Sitaru C. Transition from pemphigus foliaceus to bullous pemphigoid: intermolecular B-cell epitope spreading without IgG subclass shifting. Journal of the American Academy of Dermatology. 2009;61(2):333-6.

48. Chorzelski TP, Maciejowski E, Jablonska S, DeMento FJ, Grover RW, Holubar $\mathrm{K}$, et al. Coexistence of pemphigus and bullous pemphigoid. Archives of dermatology. 1974;109(6):849-53.

49. Korman NJ, Stanley JR, Woodley DT. Coexistence of pemphigus foliaceus and bullous pemphigoid. Demonstration of autoantibodies that bind to both the pemphigus foliaceus antigen complex and the bullous pemphigoid antigen. Archives of dermatology. 1991;127(3):387-90.

50. Matsubara K, Kanauchi H, Tanaka T, Imamura S. Coexistence of pemphigus and bullous pemphigoid. J Dermatol. 1995;22(1):68-71.

51. Tabuchi K, Nomura M, Murashita H, Fujisawa $Y$, Tsuji S, Okubo $H$, et al. Coexistence of pemphigus vulgaris and bullous pemphigoid in the upper aerodigestive tract. Auris, nasus, larynx. 2006;33(2):231-3.

52. Zakka LR, Keskin DB, Reche P, Ahmed AR. Relationship between target antigens and major histocompatibility complex (MHC) class II genes in producing two pathogenic antibodies simultaneously. Clin Exp Immunol. 2010;162(2):224-36.

53. Buhac J, Bhol K, Padilla T, Jr., Foster CS, Ahmed AR. Coexistence of pemphigus vulgaris and ocular cicatricial pemphigoid. Journal of the American Academy of Dermatology. 1996;34(5 Pt 2):884-6. 
54. Sami N, Bhol KC, Beutner EH, Plunkett RW, Leiferman KM, Foster CS, et al. Simultaneous presence of mucous membrane pemphigoid and pemphigus vulgaris: molecular characterization of both autoantibodies. Clinical immunology. 2001;100(2):219-27.

55. Fairley JA, Woodley DT, Chen M, Giudice GJ, Lin MS. A patient with both bullous pemphigoid and epidermolysis bullosa acquisita: an example of intermolecular epitope spreading. Journal of the American Academy of Dermatology. 2004;51(1):118-22.

56. Yang B, Wang C, Wu M, Du D, Yan X, Zhou G, et al. A case of pemphigoid gestationis with concurrent IgG antibodies to BP180, BP230 and type VII collagen. The Australasian journal of dermatology. 2014;55(1):e15-8.

57. Kirtschig G, Chow ET, Venning VA, Wojnarowska FT. Acquired subepidermal bullous diseases associated with psoriasis: a clinical, immunopathological and immunogenetic study. The British journal of dermatology. 1996;135(5):738-45.

58. Chan LS, Soong HK, Foster CS, Hammerberg C, Cooper KD. Ocular cicatricial pemphigoid occurring as a sequela of Stevens-Johnson syndrome. Jama. 1991;266(11):1543-6.

59. Reddy H, Shipman AR, Wojnarowska F. Epidermolysis bullosa acquisita and inflammatory bowel disease: a review of the literature. Clinical and experimental dermatology. 2013;38(3):225-9; quiz 9-30.

60. Paige DG, Leonard JN, Wojnarowska F, Fry L. Linear IgA disease and ulcerative colitis. The British journal of dermatology. 1997;136(5):779-82.

61. Harrison PV, Blewitt RW, Allen J, Wojnarowska F, Adamson AR, Jones CJ, et al. Bullous pemphigoid and ulcerative colitis: a report of two cases and description of immunoblot findings. The British journal of dermatology. 1996;134(3):599-600. 


\section{APRESENTAÇÃO EM CONGRESSOS}

Resultados parciais deste trabalho foram apresentados no $71^{\circ}$ meeting da Academia Americana de Dermatologia (AAD) em Março de 2013. 